UNIVERSIDADE REGIONAL DE BLUMENAU-FURB CENTRO DE CIÊNCIAS EXATAS E NATURAIS-CCEN CURSO DE PÓS-GRADUAÇÃO EM QUÍMICA

SÍNTESE E CARACTERIZAÇÃO DO NÚCLEO PIRIDO[2,3-g]QUINOLÍNICO SUBSTITUIDO E AVALIAÇÃO DE SUAS PROPRIEDADES CITOTÓXICAS

Ranieri Campos

BLUMENAU-SC

ABRIL DE 2006 


\section{SÍNTESE E CARACTERIZAÇÃO DO NÚCLEO PIRIDO[2,3-g]QUINOLÍNICO SUBSTITUÍDO E VALIAÇÃO DE SUAS PROPRIEDADES CITOTÓXICAS}

Dissertação apresentada ao Programa de PósGraduação em Química do Centro de Ciências Exatas e Naturais da Universidade Regional de Blumenau como requisito parcial para a obtenção do grau de Mestre em química.

Prof $^{\mathrm{a}}$. Dr ${ }^{\mathrm{a}}$. Iêda Maria Begnini-Orientadora

BLUMENAU - SC

ABRIL DE 2006 


\section{SÍNTESE E CARACTERIZAÇÃO DO NÚCLEO PIRIDO [2,3-g]QUINOLÍNICO SUBSTITUIDO E AVALIAÇÃO DE SUAS PROPRIEDADES CITOTÓXICAS}

Por

\section{RANIERI CAMPOS}

Dissertação apresentada para a obtenção do título de mestre em química pela banca examinadora formada por:

Presidente: Prof ${ }^{a}$. Dr ${ }^{\mathrm{a}}$. Iêda Maria Begnini-Orientadora - FURB

Membro: Prof. Dr. Paulo César de Jesus - FURB

Membro: Prof. Dr. Rivaldo Niero - UNIVALI

Blumenau, 20 de Abril de 2006. 
"Pai, dedico este trabalho a você, que lá de cima sempre olha por mim e me dá força necessária pra seguir em frente com meu sonko. Ebrigado."

“ Fu só gostaria de dizer que sei o quanto foi dificil conviver com tantas ausências, caras feias, esperas e impaciências.......obrigado." 


\section{AGRADECIMENTOS}

Agradeço sempre em primeiro lugar a Deus fonte de força para a realização de meus sonhos.

Agradeço a minha mãe e meus irmãos, sempre dispostos a dar uma palavra de apoio nos momentos difíceis.

Agradeço do fundo de meu coração à professora Iêda pela orientação, e mais do que isso, pelo carinho e amizade que ela sempre demonstrou ter por mim.

Ao professor Ricardo, que mesmo sempre com muita pressa arrumava um tempinho para me ajudar e encarava o laboratório com a gente.

A minha colega e amiga Melissa, que sempre me oferecia seu ombro amigo para chorar e também pelos momentos que sorrimos juntos no laboratório.

Aos colegas de mestrado Alberto Joel, Sandra, Suzete, Silvana e a Aninha por todos os nossos momentos juntos nesta jornada.

Aos amigos Giovana e Johnny que sempre prestaram ajuda em todos os momentos, pelo tempo disponibilizado, muitas vezes deixando suas próprias coisas de lado para ajudar.

A todos os colegas do laboratório de pesquisa, pela amizade e companheirismo.

Agradeço a Prof ${ }^{a}$ Juliane do departamento de parasitologia da FURB pelas orientações referentes às análises de citotoxicidade dos compostos sintetizados e também pela intermediação das amostras entre nós e o departamento de parasitologia da UFSC.

A todos os professores e funcionários do departamento de química da FURB.

Ao departamento de parasitologia da UFSC pela avaliação das propriedades citotóxicas dos compostos sintetizados e também agradeço a central de análise do departamento de química da UFRGS pelos serviços prestados. 
"Atinda que eu falasse a lingua dos homens, e falasse a lingua dos anjos, sem amor eu nada seria."

Luis de Camões 


\section{RESUMO}

As piridoquinolinas são compostos heterocíclicos diazaantracênicos que apresentam propriedades citotóxicas. Segundo a Organização Mundial da Saúde, a leishmaniose e a tripanossomíase são problemas crescentes de saúde pública, sendo endêmicos particularmente na América Latina. Os fármacos utilizados no tratamento destas doenças foram desenvolvidos há muitas décadas, e apresentam pouca eficácia e fortes efeitos colaterais. A importância biológica das piridoquinolinas e o interesse em descobrir novos agentes leishmanicidas e tripanocidas estimularam a síntese de pirido[2,3-g]quinolinas substituídas, e a avaliação do seu potencial leishmanicida e tripanocida. Assim, este trabalho descreve a síntese de diazatriciclos empregando a reação de termociclização do bis-aduto fenilenodiamínico do ácido de Meldrum. O bis-aduto 2,5-dimetil-1,4-bis[(2,2-dimetil-4,6-dioxo-1,3-dioxano-5-ilidenometil)amino]benzeno foi obtido em bom rendimento pela condensação do ácido de Meldrum com a 2,5dimetil-1,4-fenilenodiamina em ortoformato de trimetila. A termociclização em éter difenílico foi acompanhada pela eliminação espontânea de acetona e dióxido de carbono gerando o diazatriciclo, que foi clorado sem prévia purificação com oxicloreto de fósforo originando a 4,9dicloro-5,10-dimetil-pirido[2,3-g]quinolina, em rendimentos baixos. A reação de substituição nucleofílica com o 2-amino-5-dietilaminopentano foi repetida várias vezes em diferentes condições reacionais, mas não se obteve o produto esperado, necessitando da busca de novos procedimentos e otimização das condições de reação. Os compostos obtidos foram caracterizados por técnicas espectroscópicas de IV e RMN ${ }^{1} \mathrm{H}$. A avaliação das propriedades leishmanicida e tripanocida foi feita para o composto 4,9-dicloro-5,10-dimetil-pirido[2,3g]quinolina, porém o mesmo não apresentou qualquer atividade.

Palavras-chave: síntese, avaliação leishmanicida e tripanocida, pirido[2,3-g]quinolinas. 


\begin{abstract}
The pyridoquinolines are heterocyclic diazaantracenic compounds that have showed cytotoxic activity. According to the Health's World Organization, leishmaniasis and trypanossomiasis are growing problems of public health, being endemic particularly in Latin America. The medicines utilized in the handling of these illnesses were developed many decades ago, and they show a low efficacy and strong side effects. The biological importance of the pyridoquinolines, and the interest in discovering new agents leishmanicides and trypanocides have been stimulating the synthesis of substituted pyrido[2,3-g]quinolines, and the evaluation of their potential leishmanicide and trypanocide. So, this work describes the diazatricicles's synthesis, using the termociclization's reaction of the fenilenediaminic bis-adduct of Meldrum's acid. The bis-adduct 2,5-dimethyl-1,4-bis[(2,2-dimethyl-4,6-dioxo-1,3-dioxane-5ylidenomethyl)amino]-benzene has been obtained in good yield by the condensation of the Meldrum's acid with the 2,5-dimethyl-1,4-phenylenediamine in trimethylorthoformate. The termociclization in diphenylether has been accompanied for a spontaneous elimination of acetone and carbon dioxide generating the diazatricycle, that has been chlorinated without prior purification with phosphorus oxichloride, giving the 4,9-dichloro-5,10-dimethyl-pyrido[2,3g]quinoline, in low yield. The nucleophilic substitution's reaction with the 2-amine-5diethylaminepentane has been repeated several times in different reaction's conditions, but we haven't obtained the expected product, needing the search of new procedures and optimization of the reaction's conditions. The obtained compounds have been characterized by spectroscopic technicals of IV and RMN ${ }^{1} \mathrm{H}$. The evaluation of the leishmanicide and trypanocide activity was done for the compound called 4,9-dichloro-5,10-dimethyl-pyrido[2,3-g]quinoline, however it hasn't even presented any activity.
\end{abstract}

Key-words: synthesis, leishmanicide and trypanocide evaluation, pyrido[2,3-g]quinolines. 


\section{ÍNDICE GERAL}

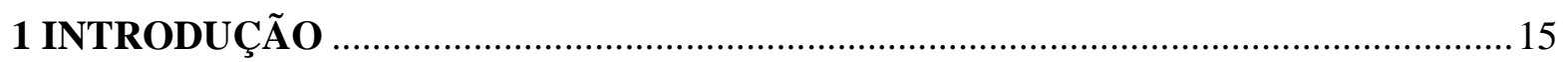

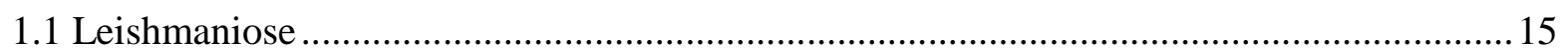

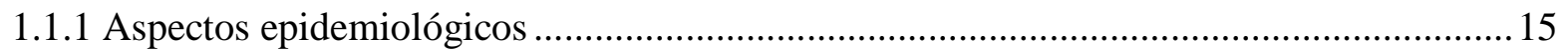

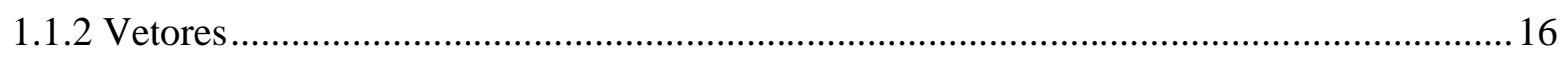

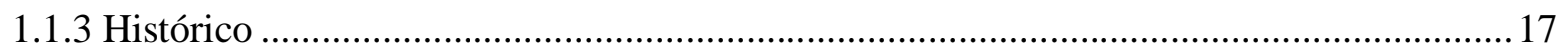

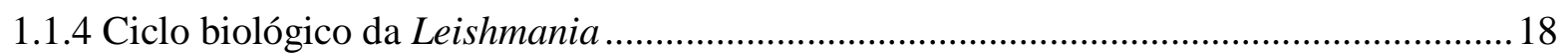

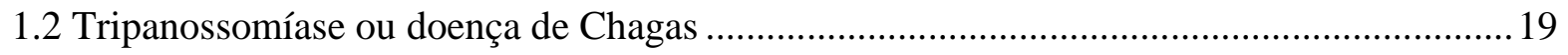

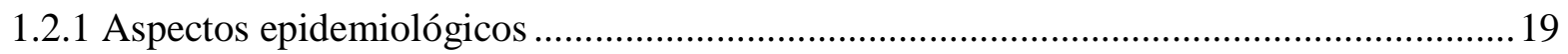

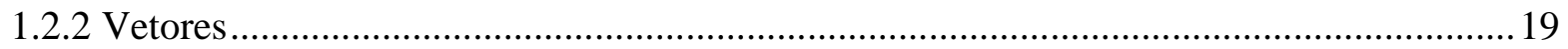

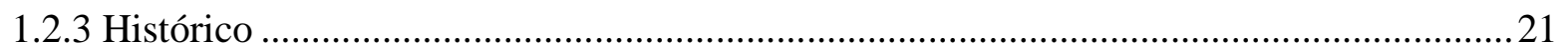

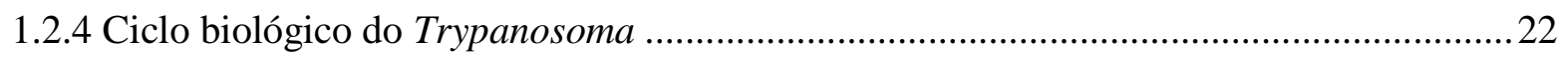

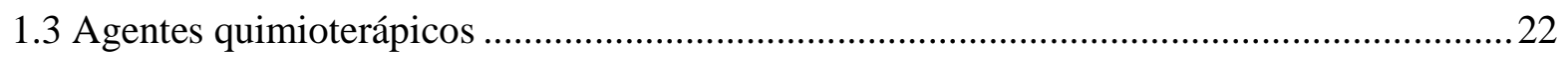

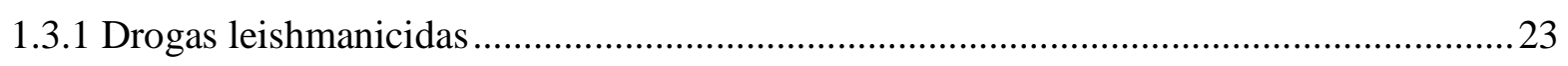

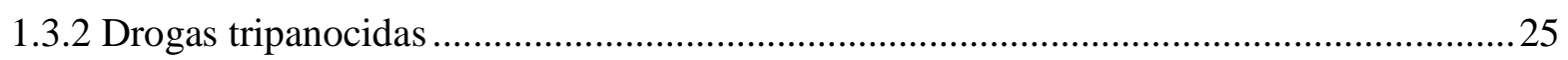

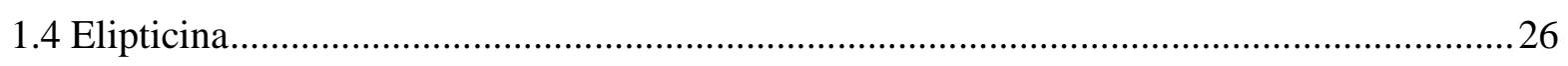

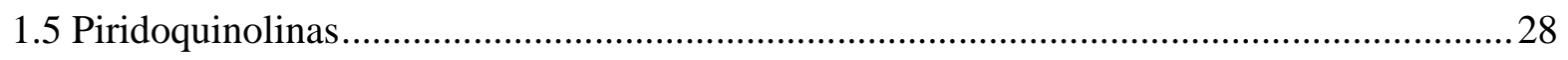

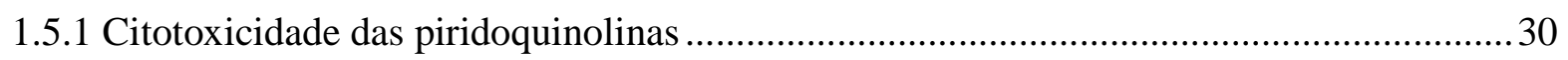

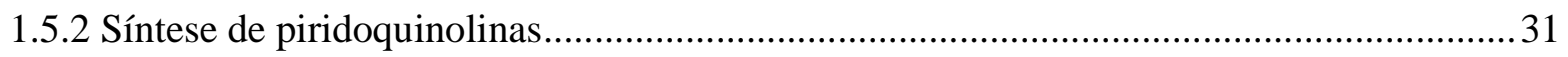

1.5.3 Substituição nucleofílica em compostos quinolínicos....................................................... 33

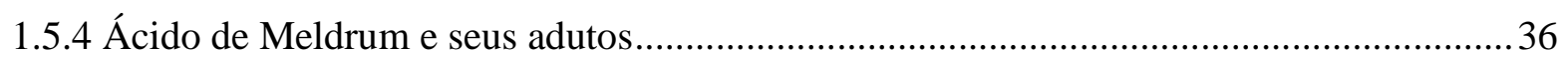

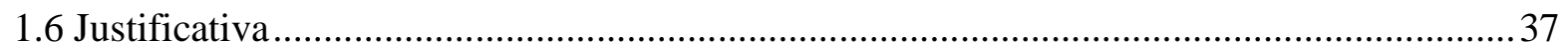

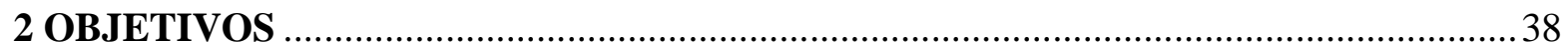

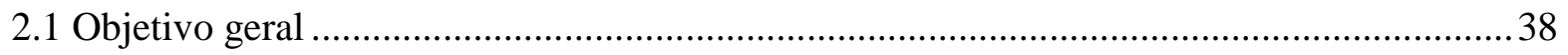

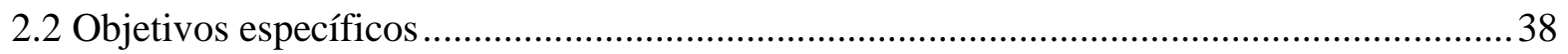

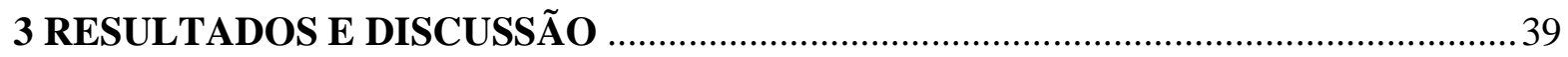

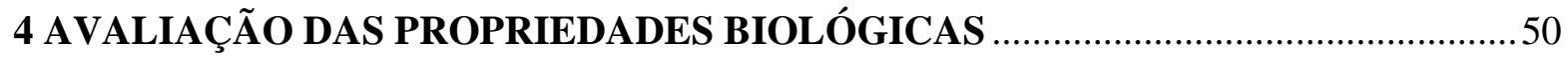


5 PARTE EXPERIMENTAL

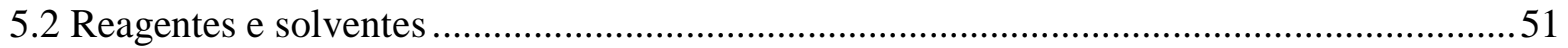

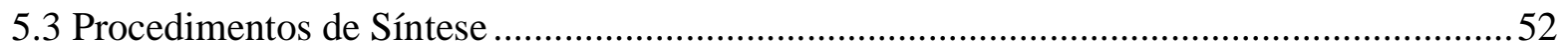

5.3.1 Preparação da 2,2-dimetil-1,3-dioxano-4,6-diona (ácido de Meldrum)...........................52

5.3.2 Preparação do 2,5-dimetil-1,4-bis-[(2,2-dimetil-4,6-dioxo-1,3-dioxano-5-

ilidenometil)amino]-benzeno (aduto do ácido de Meldrum) ...................................................53

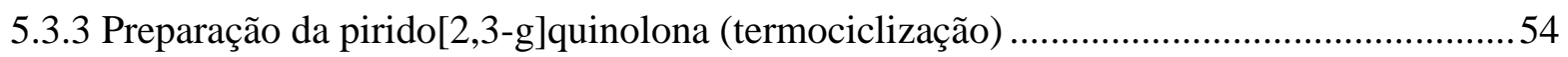

5.3.4 Preparação da 4,9-dicloro-5,10-dimetil-pirido[2,3-g]quinolina .......................................54

5.3.5 Preparação da pirido[2,3-g]quinolina substituída..........................................................55

6 PROTOCOLOS PARA AVALIAÇÃO DA ATIVIDADE BIOLÓGICA ........................56

6.1 Composto avaliado (4,9-dicloro-5,10-dimetil-pirido[2,3-g]quinolina) ...............................56

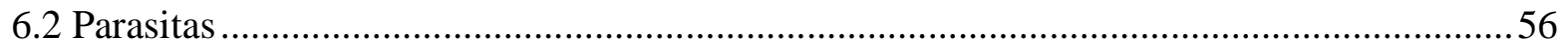

6.3 Avaliação "in vitro" da atividade antiparasitária da 4,9-dicloro-5,10-dimetil-pirido[2,3-

g]quinolina contra formas epimastigotas de T. cruzi e promastigotas de Leishmania spp .........56

6.4 Avaliação "in vitro" da atividade tripanocida e leishmanicida da 4,9-dicloro-5,10-dimetil-

pirido[2,3-g]quinolina contra formas amastigotas de T. cruzi e Leishmania spp ......................57

7 CONCLUSÃO

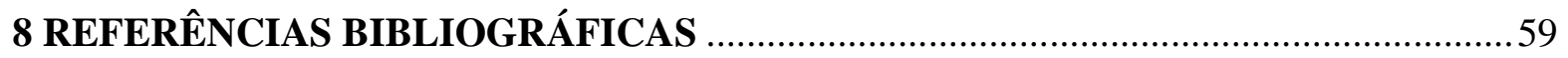




\section{ÍNDICE DAS FIGURAS}

Figura 1 - Distribuição endêmica da Leishmaniose no mundo em vermelho ............................ 15

Figura 2 - Distribuição de Leishmaniose no Brasil, de 1997 a 2003, por região ........................ 16

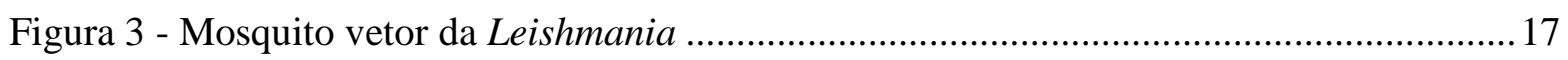

Figura 4 - Espécies do gênero Triatoma, vetores da doença de Chagas $\left(1^{\circ}\right.$ infestans; $2^{\circ}$

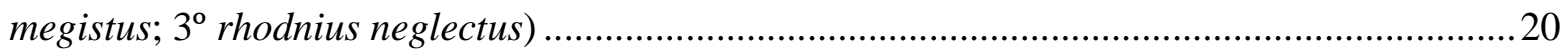

Figura 6 - Isômeros pirido[2,3-g]quinolina e pirido[3,2-g]quinolina......................................29

Figura 7 - Espectro de infravermelho do aduto do ácido de Meldrum (37) em KBr .................42

Figura 8 - Espectro de infravermelho da pirido[2,3-g]quinolona (38) em $\mathrm{KBr}$.......................43

Figura 9 - Cromatograma da pirido[2,3-g]quinolina clorada (39) ........................................45

Figura 10 - Espectro de massas da pirido[2,3-g]quinolina clorada (39) e três de seus

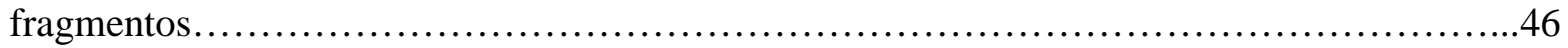

Figura 11 - Espectro de infravermelho da pirido[2,3-g]quinolina clorada (39) em $\mathrm{KBr}$..........46

Figura 12 - Espectro de RMN ${ }^{1} \mathrm{H}$ em $200 \mathrm{MHz}$ da pirido[2,3-g]quinolina clorada (39) em

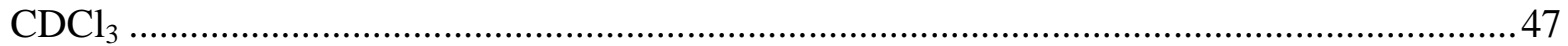

Figura 13 - Espectro de infravermelho da pirido[2,3-g]quinolina substituída (40) em $\mathrm{CH}_{2} \mathrm{Cl}_{2} .48$ 


\section{ÍNDICE DE ESQUEMAS}

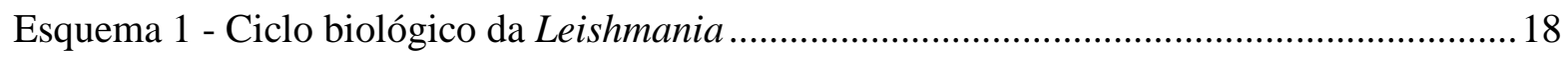

Esquema 2 - Condensação de Friedländer.................................................................................. 32

Esquema 3 - Síntese via catálise por transferência de fases ..................................................... 32

Esquema 4 - Adição de Michael a fenilenodiaminas ................................................................... 33

Esquema 5 - Representação esquemática do mecanismo de uma substituição nucleofílica .......34

Esquema 7 - Síntese utilizada por Gallo para obtenção de piridoquinolinas substituídas ..........35

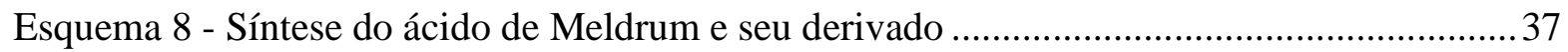

Esquema 9 - Rota sintética proposta para a síntese do composto substituído.............................39

Esquema 10 - Preparação do ácido de Meldrum e seu derivado ................................................ 40

Esquema 11 - Preparação do aduto do ácido de Meldrum ........................................................... 41

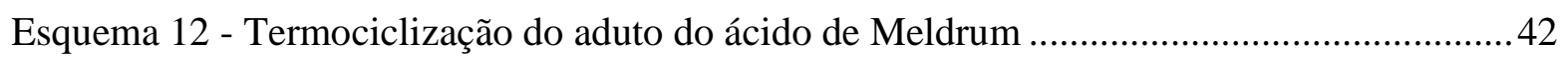

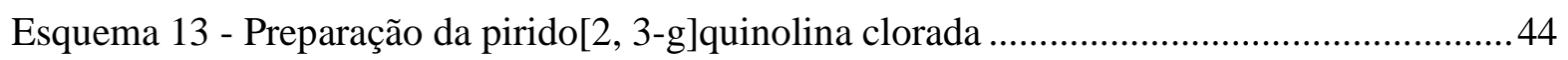

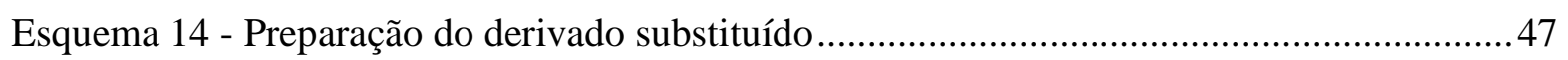




\section{LISTA DE ABREVIAÇÕES}

\begin{tabular}{|c|c|}
\hline Ác. & Ácido \\
\hline $\mathrm{Ac}_{2} \mathrm{O}$ & Anidrido acético \\
\hline AIDS & Síndrome de Imunodeficiência Adquirida \\
\hline CCD & Cromatografia em camada delgada \\
\hline Dec. & decomposição \\
\hline DNA & Ácido Desoxirribonucléico \\
\hline Et & Etila \\
\hline EtOH & Etanol \\
\hline EMME & Etoximetilenomalonato de dietila \\
\hline $\mathbf{H}$ & Hidrogênio \\
\hline $\mathbf{H z}$ & Hertz \\
\hline IV & Infravermelho \\
\hline Lit. & Literatura \\
\hline LG & Ligante \\
\hline Me & Metila \\
\hline mg & Miligrama \\
\hline MHz & Megahertz \\
\hline mmHg & Milímetros de mercúrio \\
\hline $\mathbf{m} / \mathbf{z}$ & Relação massa/carga \\
\hline $\mathbf{N u}^{-}$ & Nucleófilo \\
\hline OMS & Organização Mundial de Saúde \\
\hline P.F. & Ponto de fusão \\
\hline $\mathbf{P h}$ & Fenila \\
\hline ppm & Parte por milhão \\
\hline $\mathbf{R}$ & Radical \\
\hline $\mathrm{RMN}^{13} \mathrm{C}$ & Ressonância Magnética Nuclear de Carbono 13 \\
\hline $\mathbf{R M N}^{\mathbf{1}} \mathbf{H}$ & Ressonância Magnética Nuclear de Hidrogênio \\
\hline $\mathbf{R X}$ & Haleto de alquila \\
\hline
\end{tabular}


$\mathbf{S b}^{5+} \quad$ Antimônio pentavalente

SNC Sistema Nervoso Central

TBAB Brometo de Tetrabutilamônio

$\mathbf{t}-\mathbf{B u} \quad$ Tert - butila

T. cruzi Tripanossoma cruzi

TMS Tetrametilsilano

$\mathbf{v} / \mathbf{v} \quad$ Volume por volume 


\section{INTRODUÇÃO}

\subsection{Leishmaniose}

A leishmaniose é uma doença infecciosa zoonótica distribuída em todo o mundo. A Organização Mundial de Saúde (OMS) calcula cerca de um milhão de casos no mundo inteiro, com 400.000 novos casos a cada ano (IGLÉSIAS, 1997).

\subsubsection{Aspectos epidemiológicos}

A leishmania é um parasita amplamente difundido em várias partes da Ásia, África e Américas Central e do Sul. Portanto, podemos dizer que ela prevalece nos quatro continentes, sendo considerada endêmica em 88 países, dos quais 72 são países considerados em desenvolvimento (REY, 1991).

Segundo a OMS 90\% dos casos de Leishmaniose visceral são registrados em Bangladesh, Brasil, Nepal, Índia e Sudão, 90\% dos casos de Leishmaniose mucocutânea ocorrem no Brasil, Bolívia e Peru e 90\% dos casos da forma cutânea ocorrem no Afeganistão, Brasil, Irã, Peru, Arábia Saudita e Síria. A Figura 1 representa o quadro de distribuição da Leishmaniose no mundo (BASANO E CAMARGO, 2004).

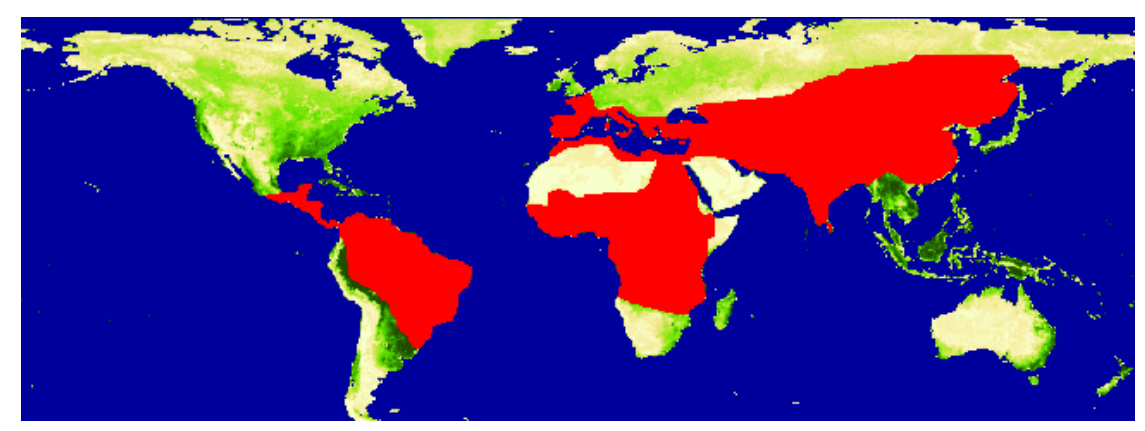

Figura 1 - Distribuição endêmica da Leishmaniose no mundo em vermelho 
No Brasil, a incidência de Leishmaniose tegumentar, um outro tipo de doença causada por esse parasita, não apresenta dados fidedignos, embora tenham sido feitas várias estimativas. Uma delas, feita de 1980 a 1990, chegou-se ao número de 154.103 casos, e outra estimativa realizada de 1985 a 1999 aponta 388.155 casos. Comparando-se os valores absolutos, houve um aumento de 13.654 casos/ano para 30.550 casos/ano nestes dois períodos, respectivamente. A Figura 2 mostra a incidência de Leishmaniose de 1997 a 2003, por região do Brasil (GONTIJO E CARVALHO, 2003).

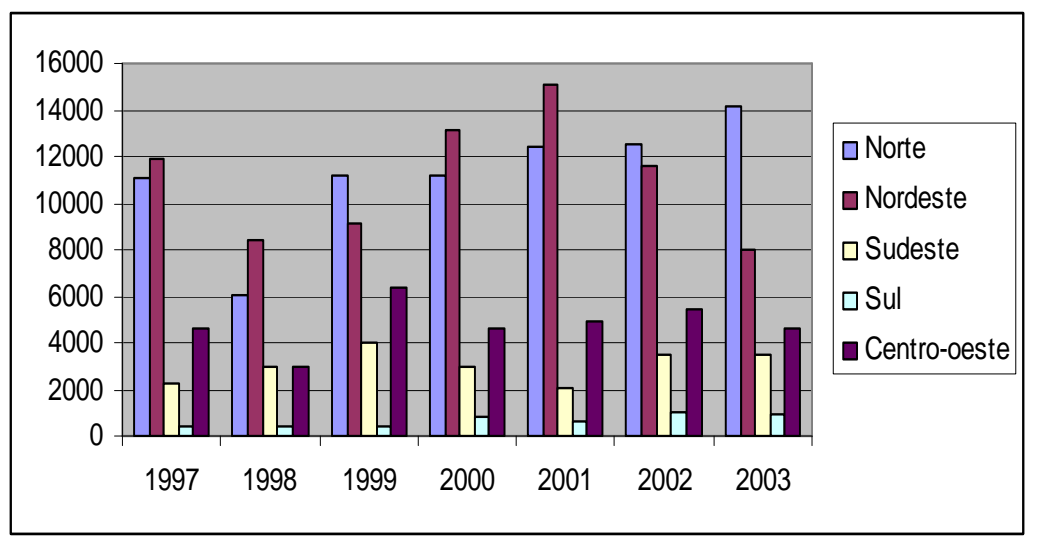

Figura 2 - Distribuição de Leishmaniose no Brasil, de 1997 a 2003, por região

\subsubsection{Vetores}

Os vetores da Leishmaniose variam conforme a espécie, mas em geral são dípteros da família Psychodida, hematófagos pertencentes ao gênero Phlebotomus e Luitzomyia, onde somente as fêmeas são hematófagas (REY, 1991).

Geralmente não ultrapassam $0,5 \mathrm{~cm}$ de comprimento, tendo pernas longas e delgadas, e o corpo densamente piloso. Tem como característica o vôo saltitante e a manutenção das asas eretas, mesmo em repouso, ao contrário dos outros dípteros. Geralmente é de cor parda, sendo que as fêmeas estão adaptadas com o respectivo aparelho bucal para picar a pele de 
vertebrados e sugar o sangue. Apresentam vários nomes populares, variando segundo os países, estados e regiões, a saber: mosquito palha, asa dura, asa branca, tatuquira, birigui, cangalha, cangalhinha, ligeirinho, péla-égua e arrupiado.

Pouco se sabe sobre seus criadouros, encontrando-se as suas formas imaturas em detritos de fendas de rocha, cavernas, raízes de solo e em folhas mortas e úmidas, e também nas forquilhinhas das árvores e em tocas de animais, ou seja, em solo úmido, mas não molhado e em detritos ricos em matéria orgânica em decomposição. Na Figura 3 temos uma foto deste mosquito (NEVES, 1997).

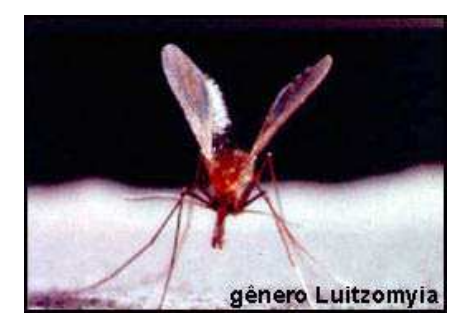

Figura 3 - Mosquito vetor da Leishmania

Os Phlebotomos dos gêneros Luitzomyia e Psychopopygus infectam-se ao picar animais portadores da doença, aspirando macrófagos parasitados ou formas amastigotas livres no sangue ou tecidos e podem transmitir a doença ao homem (REY, 1991).

\subsubsection{Histórico}

A descoberta dos agentes etiológicos das leishmanioses ocorreu só no final do século XIX, quando Cunninghan, em 1885, na Índia, descreveu casos de calazar.

Borovisky, um pesquisador russo, em 1898 mostrou tratar-se de um protozoário o agente etiológico da forma cutânea da doença (NEVES, 1997). 
No ano de 1903, várias pesquisas paralelas descreveram estes protozoários: Leishman e Donovani forneceram as primeiras impressões sobre o calazar indiano, posteriormente chamado Leishmania donovani, e Wright descreveu o parasita da forma cutânea conhecido hoje como Leishmania tropica.

A partir de 1909, também foi designado outro protozoário responsável pelo que era conhecido como ferida brava. Gaspar Viana, no Instituto Osvaldo Cruz caracterizou o que hoje é chamado Leishmania brasiliensis (PESSOA, 1988).

\subsubsection{Ciclo biológico da Leishmania}

Formas promastigotas flageladas extracelulares, livres, que vivem no trato gastrintestinal e na saliva do inseto vetor, são injetadas no hospedeiro, onde são fagocitadas pelos monócitos tissulares (macrófagos). Dentro dessas células, transformam-se em amastigotas perdendo o flagelo (mais arredondada), que residem nos fagolisosomas. No Esquema 1 está representado todo o ciclo biológico da Leishmania (MORAES, 1988).

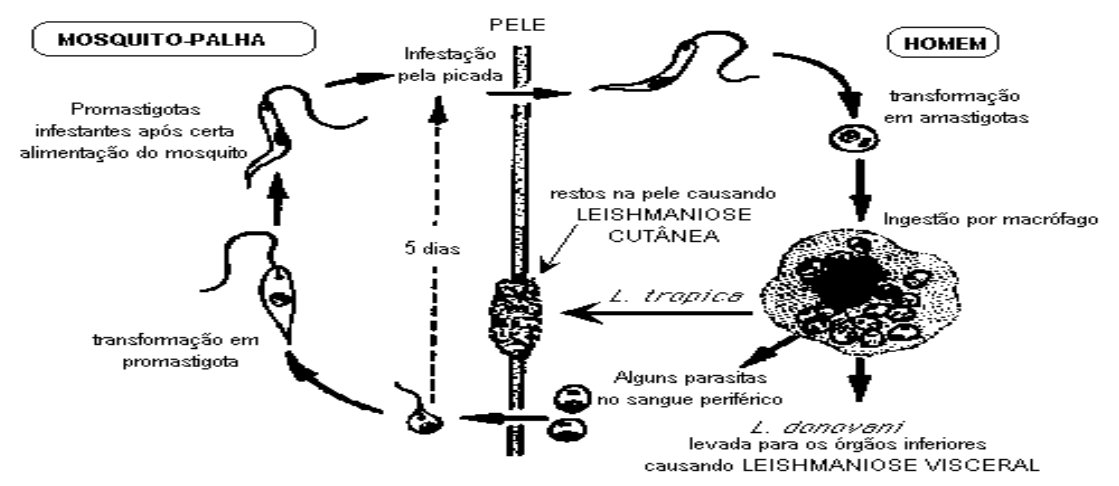

Esquema 1 - Ciclo biológico da Leishmania

A ocorrência da doença localizada ou sistêmica depende das espécies ou subespécies do parasita infectante, da distribuição dos macrófagos infectados e especialmente da resposta imune do hospedeiro (REY, 1991). 


\subsection{Tripanossomíase ou Doença de Chagas}

A Doença de Chagas estava primitivamente restrita aos pequenos mamíferos das matas e campos da América, desde a Patagônia até o sul dos Estados Unidos. Esses animais (tatus, gambás, roedores) convivem com barbeiros silvestres, e através de uma interação biológica, entre eles circula o Trypanosoma cruzi. Com a chegada do homem e os processos de colonização, em muitos lugares aconteceram desequilíbrios ecológicos (desmatamentos, queimadas) e os barbeiros foram desalojados, invadindo as habitações rústicas e pobres dos lavradores e colonos. A doença chegou ao homem e aos mamíferos domésticos (REY, 1991).

\subsubsection{Aspectos epidemiológicos}

A Tripanossomíase americana, ou Doença de Chagas, afeta cerca de 24 milhões de pessoas do sul da Califórnia até a Argentina e Chile, onde a forma crônica da doença em adultos é uma importante causa de miocardiopatia, mega esôfago, megacólon e morte. Calcula-se que no Brasil haja de 3 a 7 milhões de infectados por esta moléstia, que constitui grave problema médico - sanitário (IGLÉSIAS, 1997).

\subsubsection{Vetores}

Trypanosoma rhodeisiense e Trypanosoma gambiense são transmitidas pela mosca tsétsé (Glossina morsitans e G. palpalis, respectivamente); causam a chamada tripanossomíase africana - a primeira, tripanossomíase rodesiana e a segunda, tripanossomíase gambiense ou doença do sono, e são responsáveis pela infecção tanto no homem quanto em animais domésticos numa área de $11.650 .000 \mathrm{Km}^{2}$ na África tropical. A última espécie causa a doença 
de Chagas, cujos vetores são insetos do gênero Triatoma (principalmente o T. infestans) e Panstrongylus (principalmente o T. megistus). A Figura 4 mostra algumas espécies do gênero Triatoma, vetores da doença de Chagas (PESSOA, 1988).
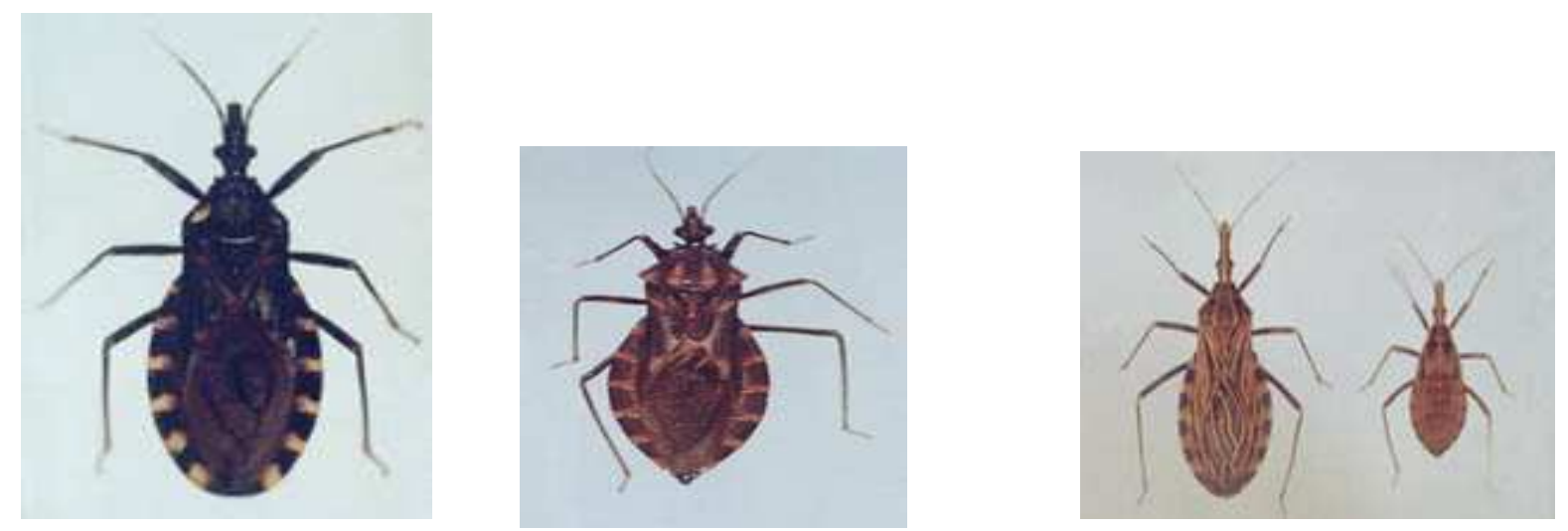

Figura 4 - Espécies do gênero Triatoma, vetores da doença de Chagas ( $1^{\circ}$ infestans; $2^{\circ}$ megistus; $3^{\circ}$ rhodnius neglectus)

O inseto vetor pica a pessoa, depositando suas fezes contaminadas na pele da vítima, transmitindo assim o Trypanosoma, que também poderá ser transmitido por transfusão de sangue contaminado e da mãe para o bebê durante a gravidez. Abrigam-se em locais muito próximos a fontes de alimento e podem ser encontrados na mata, escondidos em ninhos de pássaros, tocas de animais, cascas de troncos de árvores, montes de lenha e embaixo de pedras. Nas casas escondem-se nas frestas, buracos das paredes, nas camas, colchões e baús, além de serem encontrados em galinheiro, chiqueiro, paiol, curral e depósitos (MORAES, 1988).

Possui dois estágios, o agudo, logo após a transmissão, e que causa febre alta, mal estar, cansaço e inchaço dos gânglios, e o crônico, que poderá manifestar-se depois de uma longa evolução podendo causar lesões ao coração, esôfago, estômago e intestino. 
Em todos os tipos da doença, surge uma lesão local inicial no ponto de entrada, seguida de surtos de parasitemia e febre. O dano aos órgãos é causado pelas toxinas liberadas, afetando o sistema nervoso central (SNC), na doença do sono; o coração e, algumas vezes o fígado, o baço, os ossos e o intestino na doença de Chagas (REY, 1991).

\subsubsection{Histórico}

A Doença de Chagas ou tripanossomíase americana foi descoberta pelo médico sanitarista Carlos Justiniano Ribeiro das Chagas, mais conhecido como Carlos Chagas, no ano de 1909.

Este brasileiro descobriu a doença e descreveu praticamente todos os seus aspectos. Quando Carlos Chagas realizava uma campanha contra a malária, que atingia operários na construção de um trecho da Estrada de Ferro Central do Brasil, ao norte de Minas Gerais, ao fazer exames de uma menina doente, encontrou tripanossomas em seu sangue (PESSOA, 1988).

Ao examinar posteriormente as fezes de alguns insetos existentes na região e o sangue de animais mamíferos, constatou a presença dos mesmos parasitas encontrados anteriormente na menina.

Carlos Chagas pôde descrever o agente causador, o transmissor e o modo de transmissão desta doença, assim como também comprovar a existência de vertebrados que são reservatórios silvestres e domésticos do parasita, esclarecendo assim alguns aspectos básicos epidemiológicos apresentados por esse parasita (MORAES, 1988). 


\subsubsection{Ciclo biológico do Trypanosoma}

Este protozoário entra na células na sua forma tripomastigota que é cíclica, e proliferase nesta forma amastigota intracelularmente. Estes parasitas em forma amastigota se diferenciam intracelularmente em tripomastigotos que são liberados na circulação.

Os tripomastigotos não se multiplicam na corrente sanguínea até invadirem outras células ou serem ingeridos por um inseto vetor, que difundirá a doença para outros vertebrados, tratando-se, portanto, de um parasita de potencial endêmico (IGLÉSIAS, 1997).

\subsection{Agentes quimioterápicos}

Os agentes quimioterápicos são substâncias químicas que exercem ação sobre parasitas e células tumorais. São usados no tratamento ou controle de moléstias causadas por organismos ou células invasoras patogênicas (HANG e DALE, 1991).

O termo "quimioterapia" tem um sentido amplo. Significa o tratamento de doenças por meio de agentes químicos que, além de interferirem de modo positivo sobre uma doença, também causam efeitos tóxicos ao organismo como um todo.

O agente quimioterápico ideal possui toxicidade seletiva em relação ao parasita, mas deve ser inócuo para o hospedeiro. Uma vez que tal agente não existe, deve-se sempre levar em conta a relação risco/benefício (KOROLKOVAS, 1999).

A maioria das drogas quimioterápicas utilizadas no tratamento da Doença de Chagas e da leishmaniose foram desenvolvidas há muitas décadas atrás e, por isso, possuem muitos efeitos colaterais, requerem um longo tratamento e possuem um preço muito elevado (KOROLKOVAS, 2000). 


\subsubsection{Drogas leishmanicidas}

As leishmanioses incluem uma variedade de doenças produzidas por parasitas de diversas espécies, onde produzem lesões diferentes e, portanto, requerem tratamento diferente (HANG e DALE, 1991).

Os fármacos leishmanicidas empregados podem ser classificados nos seguintes grupos, dentre os quais se destaca o grupo dos antimoniais.

- $\quad$ Alcalóides: berberina e desidroemetina

- $\quad$ Antibióticos: anfotericina B, dactilarina e nistatina.

- $\quad$ Antimoniais: antimoniato de meglumina

- Diaminas aromáticas: pentamidina, propamidina.

Apesar do uso medicinal de compostos de antimônio já ser conhecido desde a antiguidade, para diversos fins terapêuticos, somente em 1912, Gaspar Vianna observou que o tártaro emético (1) era eficaz na terapêutica da Leishmaniose (GOLDSMITH, 1998).

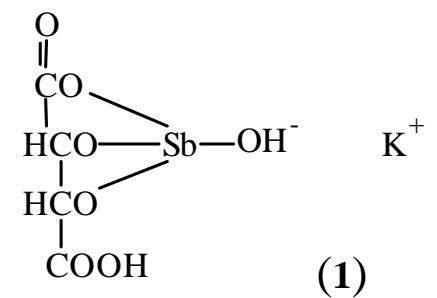

Bramachari, em 1920, desenvolveu o primeiro composto a base de antimônio pentavalente, a estibamina-uréia, derivado uréico do ácido para-aminofenil estilbínico, e em 1936, Schmidt introduziu na terapia médica o gluconato de antimônio sódico.

Devido aos efeitos colaterais indesejáveis do tártaro emético, tais como intolerância gastrintestinal e efeitos cardiotóxicos, hoje o tratamento de escolha para a forma cutânea da doença é feito com estibogluconato sódico (2). Por outro lado, para a forma visceral usa-se 
estibamina-uréia (3) e para a forma cutâneo-mucosa usa-se, preferencialmente, antimoniato de meglumina (4) (RATH, 2002).

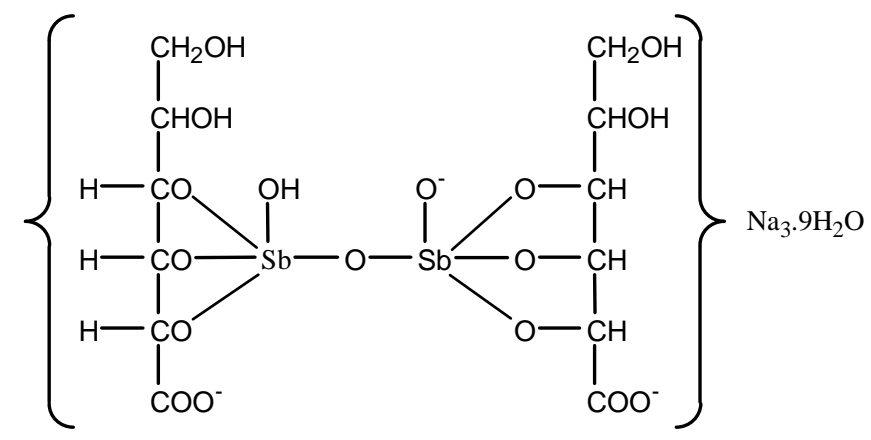

(2)<smiles>C[Sb](=O)(O)c1ccc(NC(N)=O)cc1</smiles>

(3)<smiles>CNCC(O)C(O)C(O)C(O)CO</smiles>

(4)

Visando produzir o esquema terapêutico, a Organização Mundial de Saúde recomenda que a dose do antimonial seja calculada em $\mathrm{mg} / \mathrm{Sb}^{5+} / \mathrm{Kg} /$ dia (onde $\mathrm{Sb}^{5+}=$ antimônio pentavalente). $\mathrm{O}$ antimoniato de meglumina é comercializado em frascos de $5 \mathrm{~mL}$ que contém $1,5 \mathrm{~g}$ de antimoniato bruto, correspondente a $425 \mathrm{mg} \mathrm{de} \mathrm{Sb}^{5+}$ (KOROLKOVAS, 2000).

A anfotericina B (5) é um antibiótico antifúngico derivado de uma cepa de Estreptomyces nodosus, indicado para o tratamento da Leishmaniose mucocutânea americana, mas não é o medicamento de primeira escolha. Ela é empregada quando não se tem resposta com a terapêutica antimonial ou na impossibilidade de seu uso. É apresentada em frascos de 
$50 \mathrm{mg}$ para uso endovenoso. A dose inicial de $0,5 \mathrm{mg} / \mathrm{Kg} / \mathrm{dia}$ deve ser aumentada gradativamente, conforme a tolerância do paciente, até 1 mg/Kg/dia (HANG e DALE, 1991).

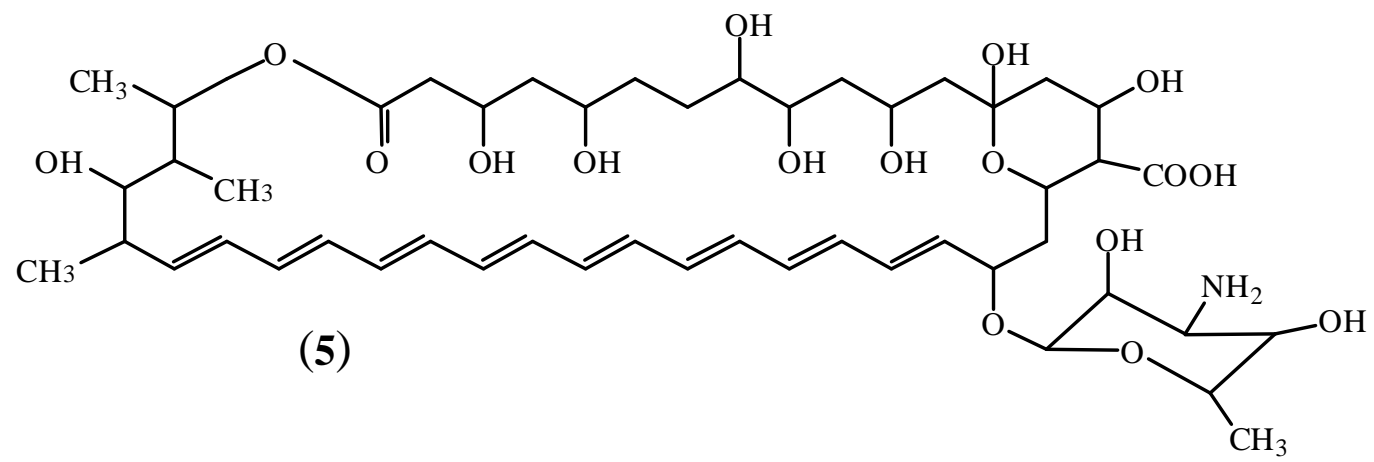

\subsubsection{Drogas tripanocidas}

O medicamento de escolha para o tratamento da tripanossomíase americana (doença de Chagas) é o nifurtimox (6). Agentes nitro-heterocíclicos como o nifurtimox (6) e o benzonidazol (7) podem suprimir a parasitemia e melhorar ou até curar a fase aguda da doença de Chagas, entretanto, esses agentes tóxicos têm pouco efeito na fase crônica. T. cruzi é especialmente vulnerável a fármacos que formam radicais livres intracelulares. Tanto o nifurtimox, como o benzonidazol tem essa capacidade e outros agentes com propriedades semelhantes estão sendo investigados (HANG e DALE, 1991).<smiles>CC1C[Sb](=O)(O)CCN1N=Cc1ccc([N+](=O)[O-])o1</smiles><smiles>O=C(Cn1ccnc1[N+](=O)[O-])NCc1ccccc1</smiles> 
O nifurtimox (6) apresenta-se na forma de cristais vermelho-alaranjados. É eficaz na forma aguda da Doença de Chagas em crianças e adolescentes, contudo não deve ser usado em crianças com menos de um ano (KOROLKOVAS, 2000).

O benzonidazol (7), um derivado nitroimidazólico, tem apresentado resultados promissores. Ele se apresenta como um sólido amarelo, cristalino, insolúvel em água, mas ligeiramente solúvel em álcool (KOROLKOVAS, 2000).

Em ensaios clínicos mostrou-se ativo contra o T. cruzi, em cerca de 80 a $90 \%$ dos casos, tanto na fase aguda como na fase crônica da doença de Chagas. No entanto, é necessário que se esclareça que um tratamento específico para a doença de Chagas ainda encontra-se em andamento (RATH, 2002).

Os fármacos utilizados para o tratamento da tripanossomíase africana são a suramina, a pentamidina e o melarsoprol (HANG e DALE, 1991).

\subsection{Elipticina}

A elipticina (8) é uma molécula encontrada naturalmente na planta Ochrosia elíptica, isolada inicialmente em 1959, que cresce livremente na Oceania. Trata-se de um alcalóide, incorporando à sua estrutura planar um anel benzênico dimetilado, separando dois núcleos aromáticos nitrogenados. Podemos descrever ainda sua estrutura como um grupamento carbazol ligado ao anel da piridina. 


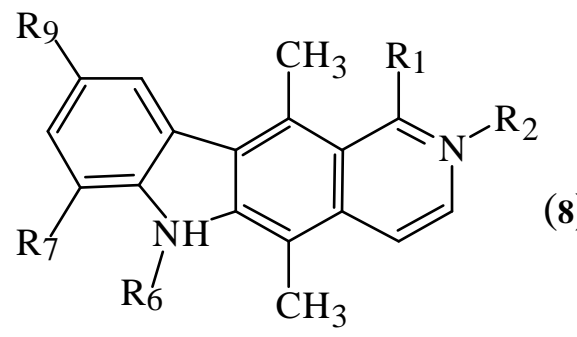

Elipticina, $\mathrm{R}=\mathrm{H}$

Por possuir esta estrutura química distinta, acontece um deslocamento eletrônico que se estende sobre toda a molécula. Além disso, esta estrutura tem permitido a síntese de mais de 70 análogos distintos, com as principais modificações sendo a inclusão de um grupo hidroxila nas posições $\mathrm{C}_{9}$ e $\mathrm{C}_{7}$, e alquilação nas posições $\mathrm{N}_{2}, \mathrm{~N}_{6}$ e $\mathrm{C}_{1}$. Mais recentemente, novas elipticinas substituídas em $\mathrm{C}_{9}$ foram sintetizadas visando obter derivados com citotoxicidade seletiva (CIRINO, BELLETO e DANTAS, 2005).

A elipticina (8) e alguns de seus derivados apresentam pronunciada atividade citotóxica e antitumoral, sendo utilizados na quimioterapia do câncer e em tratamentos experimentais da Síndrome de Imunodeficiência Adquirida (AIDS). Atividade leishmanicida e tripanocida também tem sido relatada. Alguns trabalhos atestam que o principal interesse clínico se relaciona com seus efeitos tóxicos limitados e sua completa falta de toxicidade hematológica (CIRINO, BELLETO e DANTAS, 2005).

O mecanismo de ação dessas drogas pode envolver intercalação com as bases do DNA. Muitos estudos envolvendo elipticinas constataram uma relação entre sua atividade antitumoral e a magnitude do momento de dipolo. Para o mesmo grupo de moléculas, foi estudada a intercalação de uma molécula de elipticina entre dois pares de bases do DNA, 
verificando-se uma preferência pela intercalação entre os pares citosina-guanina (MOLOCK, 1983).

Segundo Cirino e colaboradores, uma diminuição da polaridade e aumento do volume molecular favorece o processo de intercalação com o DNA. A diminuição da densidade de cargas no átomo $\mathrm{N} 6$ e a presença de substituintes retiradores de elétrons em $\mathrm{C}_{9}$ levam a um aumento na constante de associação com o DNA (CIRINO, BELLETO e DANTAS, 2005).

De acordo com os trabalhos de Auclair, a hidroxilação da posição $\mathrm{C}_{9}$ é uma modificação molecular importante, sendo esta modificação relacionada com a possibilidade de formação de ligação de hidrogênio das elipticinas com os grupos fosfato (AUCLAIR, 1987).

De acordo com Dantas, um baixo efeito citotóxico foi correlacionado com a alta densidade eletrônica em $\mathrm{N}_{6}$. As posições "R" são locais onde são feitas as várias modificações moleculares visando melhorar a atividade citotóxica (DANTAS, 1992).

Além desses excelentes resultados, as elipticinas representam alguns dos agentes quimioterápicos mais simples e não possuem problemas de controle estereoquímico em suas sínteses por serem planares.

\subsection{Piridoquinolinas}

Heterociclos como a piridina e a quinolina podem fundir-se formando alguns tipos de compostos, a saber:

- diazafenilenos;

- diazaantracenos e;

- diazafenantrenos. 
No presente trabalho, um maior enfoque é dado a compostos diazaantracênicos e algus métodos de sínteses destes compostos são descritas.

Análogos estruturais ao antraceno, ou seja, compostos lineares, são usualmente denominados piridoquinolinas.

A fusão dos anéis piridínicos com o sistema quinolínico de forma linear (piridoquinolinas) pode acontecer de duas formas (Figura 5) (KATRITZKY, 1984).<smiles></smiles><smiles></smiles>

Figura 5 - Fusão do sistema quinolínico com o anel da piridina

Com base na nomenclatura e numeração proposta para heterociclos, temos dois isômeros estruturais distintos representados na Figura 6.
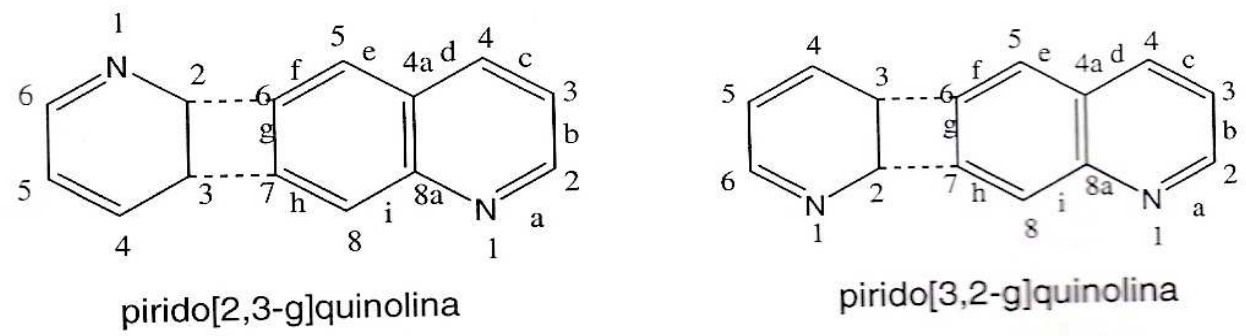

Figura 6 - Isômeros pirido[2,3-g]quinolina e pirido[3,2-g]quinolina

Observando-se o primeiro caso percebe-se que a face 2,3 do anel piridínico funde-se à face g do sistema quinolínico formando o isômero [2,3-g] piridoquinolina e, no segundo caso, a face 3,2 do anel piridínico funde-se à face $\mathrm{g}$ do sistema quinolínico formando o isômero [3,2-g] piridoquinolina (GRAF et al, 2002). 


\subsubsection{Citotoxicidade das piridoquinolinas}

Devido a uma hibridação $\mathrm{sp}^{2}$ em seus carbonos, o sistema piridoquinolínico possui como característica marcante uma estrutura planar. Além da similaridade com o alcalóide elipticina, podendo promover intercalação com o DNA, grupos protonáveis e pares de elétrons livres dos nitrogênios podem quelar as fitas do DNA, promovendo a atividade citotóxica.

Segundo Picó, três piridoquinolinas, a 4,6-Bis(dimetilaminoetóxi)-2,8,10trimetilpirido[3,2-g]quinolina (9), 4,6-Bis[(dimetilaminoetil)tio]-2,8,10-trimetilpirido[3,2g]quinolina (10) e 4,6-Bis(dimetilaminoetilamino)-2,8,10-trimetilpirido[3,2-g]quinolina (11) mostraram ótima atividade anti-proliferativa por citotoxicidade (PICÓ et al, 2001).
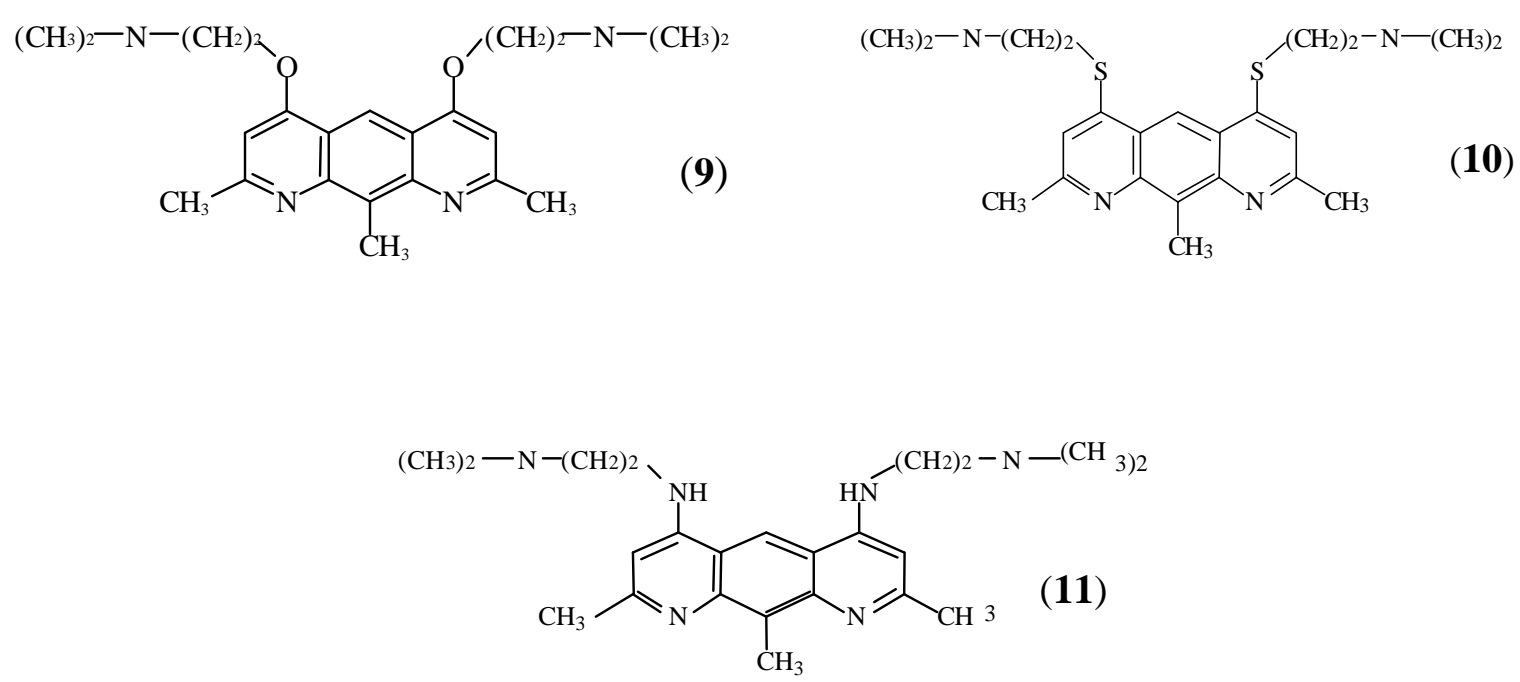

Hall e colaboradores testaram a atividade antialérgica de derivados piridoquinolínicos do tipo [2,3-g], com diferentes substituintes (12) (HALL et al, 1977). 
<smiles>[R]OC(=O)c1[nH]c2cc3c(=O)c([R])c(C([R])=O)[nH]c3cc2c(=O)c1[R]</smiles>

$\mathrm{R}=$ Metil ( 12a), etil (12b) e H (12c)

A estrutura química relativamente simples e a versatilidade de reações de substituição neste núcleo possibilitam a construção de moléculas com potencial químico e biológico muito variado, e uma gama de aplicações, bem como atividades solvatocrômicas e termocrômicas (GRAF et al, 2002).

\subsubsection{Síntese de piridoquinolinas}

Atualmente existem vários métodos para a síntese de diazatriciclos piridoquinolínicos, todos com o intuito de melhorar os rendimentos no intuito de utilizá-los como compostos citotóxicos e, além disso, investigar outras propriedades físicas e possíveis atividades biológicas.

Em rendimentos de aproximadamente $35 \%$, pode-se utilizar como estratégia de síntese uma condensação de Friedlander para a obtenção da pirido[3,2-g]quinolina substituída (15) utilizando-se como reagente de partida o aldeído 4,6-diaminoisoftálico (13), onde reagindo-se com diferentes aldeídos e cetonas, pode-se obter várias pirido[3,2-g]quinolinas as quais com diferentes substituintes, como segue no Esquema 2 (QUAST e LIEBIGS, 1984). 
<smiles>Nc1cc(N)c(C=O)cc1C=O</smiles>

(13)<smiles>[R]C(C)=O</smiles>

(14)<smiles>[R]c1ccc2cc3ccc([R])nc3cc2n1</smiles>

$\mathrm{R}=\mathrm{H}, \mathrm{Me}, \mathrm{t}-\mathrm{Bu}, \mathrm{Ph}, \mathrm{CO}_{2} \mathrm{H} \mathrm{E} \mathrm{CO} \mathrm{Ce}_{2}$ (15)

\section{Esquema 2 - Condensação de Friedländer}

Outro método de síntese leva à produção de uma dialcoxi[3,2-g]piridoquinolina (19) partindo de 2,6-diaminotolueno (16). Em bons rendimentos (85\%), o aduto 2,6bis(carboetoximetilvinilamino)tolueno (17) é formado na reação entre 2,6-diaminotolueno (16) e acetoacetato de etila, que é termociclizado em éter difenílico com rendimentos ainda maiores, 95\%, gerando uma piridoquinolona (18). Uma alcoxi[3,2-g]piridoquinolina (19) e uma série de seus derivados foram obtidos via catálise por transferência de fases com brometo de tetrabutilamônio (TBAB) em rendimentos de até 68\%, conforme Esquema 3 (MATIAS e MAHAMOUND, 1996).

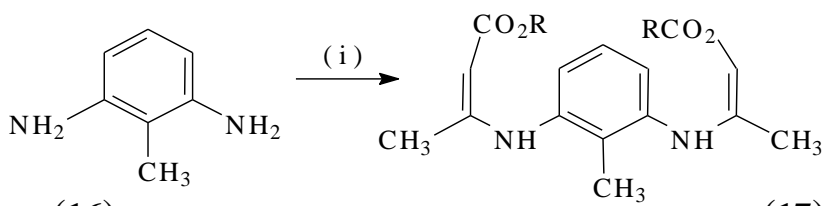

(16)<smiles>[R]Oc1cc(C)nc2c(C)c3nc(C)cc(O[R])c3cc12</smiles>

(19)

(i ) $\mathrm{CH}_{3} \mathrm{COCH}_{2} \mathrm{CO}_{2} \mathrm{C}_{2} \mathrm{H}_{5} / \mathrm{EtOH} / \mathrm{CaSO}_{4} / 80^{\circ} \mathrm{C}$; ( ii ) $\mathrm{Ph}-\mathrm{O}-\mathrm{Ph} / 250^{\circ} \mathrm{C}$ (iii ) $\mathrm{RX} /$ tolueno/ $\mathrm{KOH} 50 \% / \mathrm{TBAB} ; \mathrm{R}=\left(\mathrm{CH}_{2}\right)_{2}-\mathrm{N}-\left(\mathrm{CH}_{3}\right)_{2}$

Esquema 3 - Síntese via catálise por transferência de fases 
Uma adição de Michael a fenilenodiaminas também foi empregada para a preparação de adutos (20), os quais foram termociclizados em éter difenílico gerando piridoquinolonas (21), que após saponificação e descarboxilação, foram cloradas com oxicloreto de fósforo em bons rendimentos $(80 \%)$ gerando pirido[2,3-g]quinolinas cloradas (22), como é mostrado no Esquema 4 (MOLOCK, 1983).<smiles>CCOC(=O)C(=CNc1cccc(N(C)C)c1C)C(=O)OCc1ccccc1</smiles>

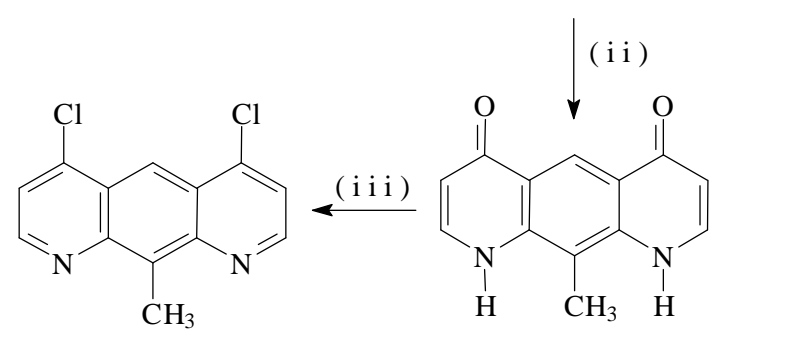

(22)

(21)

(i ) $\mathrm{EMME} / \mathrm{CuSO}{ }_{4} / \mathrm{EtOH} / 80^{\circ} \mathrm{C} / 4 \mathrm{~h}$; ( ii ) $\mathrm{Ph}-\mathrm{O}-\mathrm{Ph} / 250^{\circ} \mathrm{C} / 5 \mathrm{~min}$; ( iii ) $\mathrm{POCl}_{3} / 1 \mathrm{~h}$

Esquema 4 - Adição de Michael a fenilenodiaminas

\subsubsection{Substituição nucleofílica em compostos quinolínicos}

O mecanismo de uma substituição nucleofílica envolve a quebra de ligação no substrato e formação de ligação no produto. Nucleofilicidade e basicidade são propriedades muito similares, desta forma, espécies que são nucleófilas são geralmente também bases. Isto não é surpresa, uma vez que no conceito de Lewis, elas estão funcionando como doadores de pares de elétrons isolados. O Esquema 5 representa de uma maneira geral o mecanismo de substituição nucleofílica, onde $\mathrm{Nu}^{-}$representa um nucleófilo hipotético e LG representa um ligante que será o grupo de saída (SOLOMONS, 2001). 


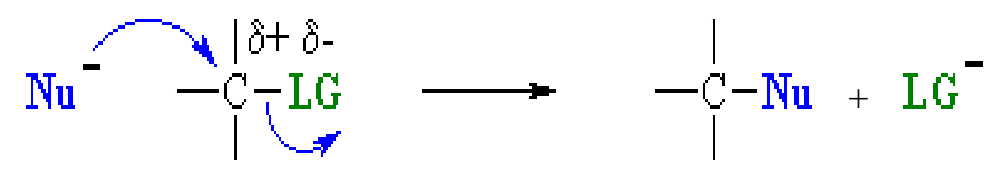

Esquema 5 - Representação esquemática do mecanismo de uma substituição nucleofílica

O entendimento do mecanismo de reações orgânicas e de ação das drogas é fundamental para a construção de novas moléculas com bom potencial farmacológico e baixa toxicidade.

Compostos quinolínicos e derivados têm, há muito tempo, mostrado atividade citotóxica. A cloroquina (23), uma molécula citotóxica, possui o grupo farmacofórico 4-aminoquinolina, que é responsável por sua atividade biológica, e o seu substituinte é o $N^{\prime}, N^{\prime}$ '-dietilamino- $N$-metilpropilenodiamina (McCAUSTLAND e CHENG, 1970).<smiles>CCN(CC)CC(C)Nc1ccnc2cc(Cl)ccc12</smiles>

Como parte de um programa geral de obtenção de novos agentes citotóxicos, muitas moléculas têm sido preparadas incorporando as propriedades do núcleo piridoquinolínico com as do substituinte da cloroquina. Substituintes nitrogenados, oxigenados e sulfatados têm sido amplamente investigados, por esta razão novas metodologias de síntese têm sido propostas. Através de reações de substituição nucleofílica do precursor clorado, Molock e colaboradores obtiveram a 4,6-Bis(3'-dimetilaminopropilamino)-10-metilpirido[3,2-g]quinolina (25) com um rendimento de 91\%, Esquema 6 (MOLOCK, 1983). 


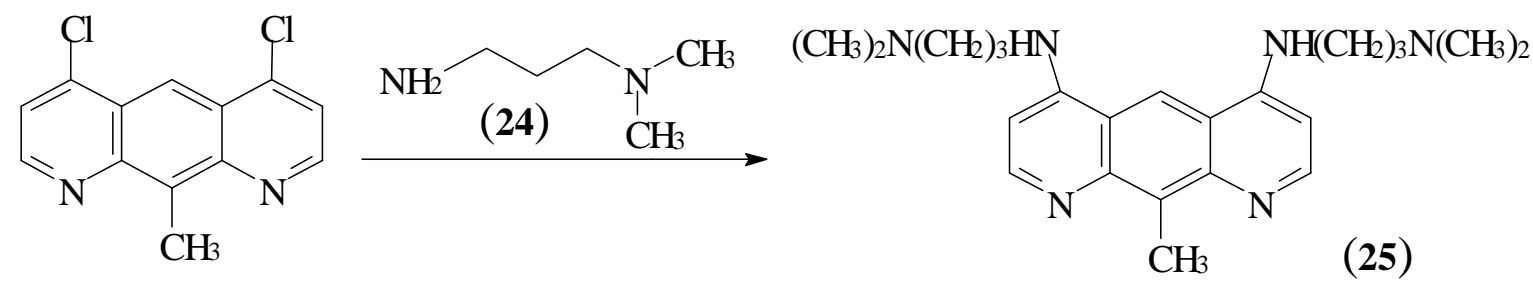

Esquema 6 - Substituição nucleofílica realizada por Molock

Gallo e colaboradores sintetizaram piridoquinolinas substituídas pela alquilação de piridoquinodionas e piridoquinotionas pelo clorobromoetano fornecendo o intermediário (27), como uma mistura do derivado clorado e bromado. A reação com aminas primárias ou secundárias leva a formação dos compostos (28) (51\%), (29) (40\%) e (30) (80\%), Esquema 7 (GALLO et al, 2003).

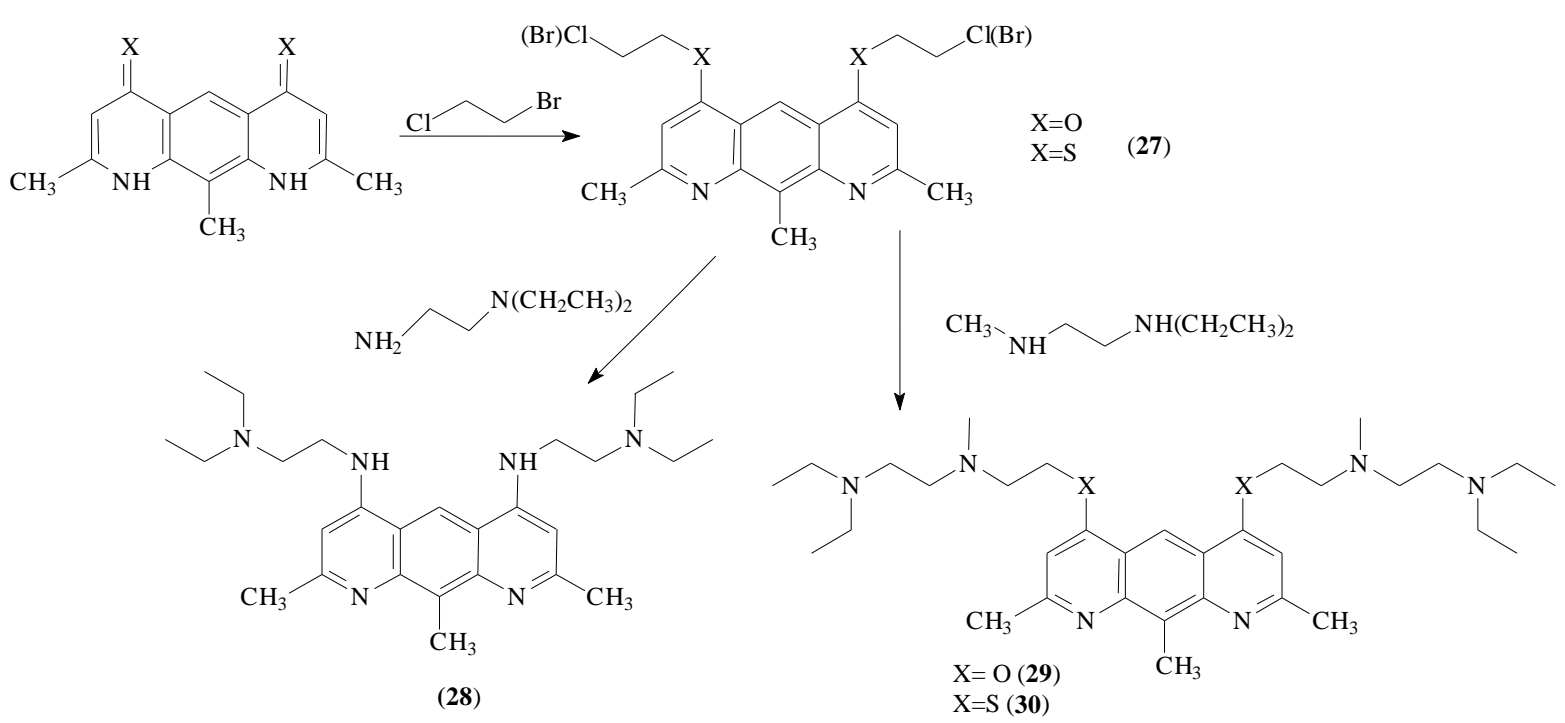

Esquema 7 - Síntese utilizada por Gallo para obtenção de piridoquinolinas substituídas

Sharples e colaboradores descreveram a obtenção de uma série de derivados monossubstituídos oxigenados (31), através de uma alquilação via catálise por transferência de fases do 2,10-dimetilpirido[3,2-g]quinolina-4-ona (SHARPLES et. al, 2005). 


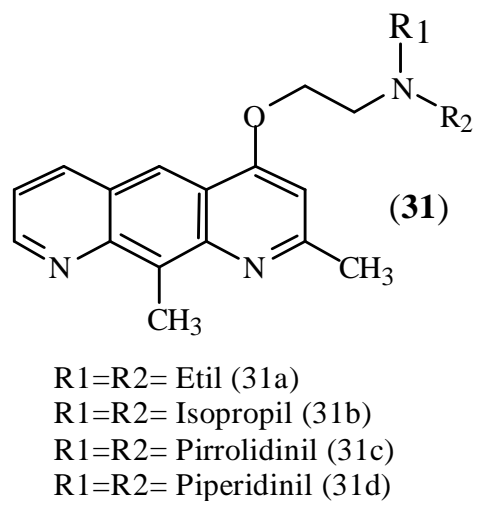

\subsection{4 Ácido de Meldrum e seus adutos}

Através da condensação de ácido malônico (32), acetona (33) e anidrido acético, utilizando como catalisador ácido sulfúrico concentrado, conforme o Esquema 8, obtém-se um sólido cristalino branco com ponto de fusão em $95^{\circ} \mathrm{C}$, de pKa 4,83 (medido em solução de DMSO) denominado 2,2-dimetil-1,3-dioxano-4,6-diona, usualmente chamado ácido de Meldrum (34) (MACKNAB, 1978).

Por apresentar uma característica anfifílica, possui um caráter eletrofílico nas posições 4 e 6, e nucleofílico na posição 5, permitindo que o anel fique intacto.

A reação deste ácido com ortoformato de trimetila gera o derivado (35) que provavelmente possui a maior importância dentro da síntese de heterociclos, atuando como intermediário-chave desses heterociclos, que leva à formação de vários adutos que são passíveis de termociclização (BANG-CHI, 1991).

Esta pirólise do ácido de Meldrum, em solução ou em fase gasosa, ocorre por perda de acetona e dióxido de carbono para gerar um intermediário do tipo ceteno.

Dentre as aplicabilidades deste ácido podem ser citadas a produção de indóis e heterociclos. 


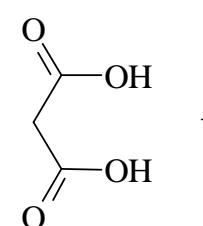

(32)<smiles>CC(C)=O</smiles>

(33)
(34)

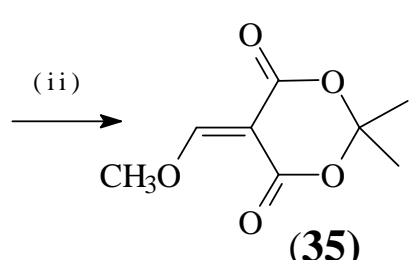

(35)

(i ) $\mathrm{Ac}_{2} \mathrm{O} / \mathrm{H}_{2} \mathrm{SO}_{4}$; ( $\mathrm{i}$ i ) Ortoformato de trimetila

Esquema 8 - Síntese do ácido de Meldrum e seu derivado

\subsection{Justificativa}

Em pleno século XXI as doenças parasitárias ainda constituem um dos principais problemas de saúde pública no Brasil e no mundo. A doença de Chagas, a leishmaniose e a malária são exemplos de graves doenças causadas por protozoários que continuam a ameaçar principalmente a população brasileira mais carente.

Há bastante tempo, a busca da cura dessas doenças motiva uma parcela significativa de pesquisadores que atuam, em todo o mundo, na área de saúde pública, na química e em outras ciências correlatas, sempre em trabalhos multidisciplinares. Porém, as inúmeras descobertas ainda não levaram a uma solução efetiva desses problemas. É urgente, portanto, o desenvolvimento de novas drogas, a promoção de parcerias com companhias farmacêuticas e universidades, o estabelecimento de redes de triagem (verificação de atividade biológica) de produtos naturais ou sintéticos e da melhoria da capacitação de pesquisadores, principalmente nos países tropicais onde essas doenças são endêmicas (BASANO e CAMARGO, 2004).

Neste sentido, o presente trabalho enfoca a síntese de novos possíveis agentes citotóxicos mais seletivos, com menor toxicidade hematológica através da combinação de análogos da elipticina com as propriedades do substituinte da cloroquina, os quais apresentam pronunciada citotoxicidade. 


\section{OBJETIVOS}

\subsection{Objetivo geral}

- Sintetizar o núcleo pirido[2,3-g]quinolínico substituído e avaliar o seu potencial citotóxico.

\subsection{Objetivos específicos}

- Sintetizar o núcleo pirido[2,3-g]quinolínico clorado.

- Realizar uma substituição nucleofílica no núcleo pirido[2,3-g]quinolínico com nucleófilo nitrogenado.

- Caracterizar espectroscopicamente os compostos obtidos.

- Avaliar "in vitro" as propriedades leischmanicida e tripanocida do composto clorado.

- Avaliar "in vitro" as propriedades leischmanicida e tripanocida do composto substituído. 


\section{RESULTADOS E DISCUSSÃO}

O Esquema 9 mostra de maneira geral a rota sintética escolhida para a obtenção da 4,9-dicloro-5,10-dimetilpirido[2,3-g]quinolina, e sua posterior substituição nucleofílica.<smiles>Cc1cc(NC=C2C(=O)OC(C)(C)OC2=CNc2cc(C)c(NC=C3C(=O)OC(C)(C)OC3=O)cc2C)c(C)cc1N</smiles><smiles>C=Nc1c(C(=C)Cl)c(C)c2nccc(Cl)c2c1C</smiles>

(39)

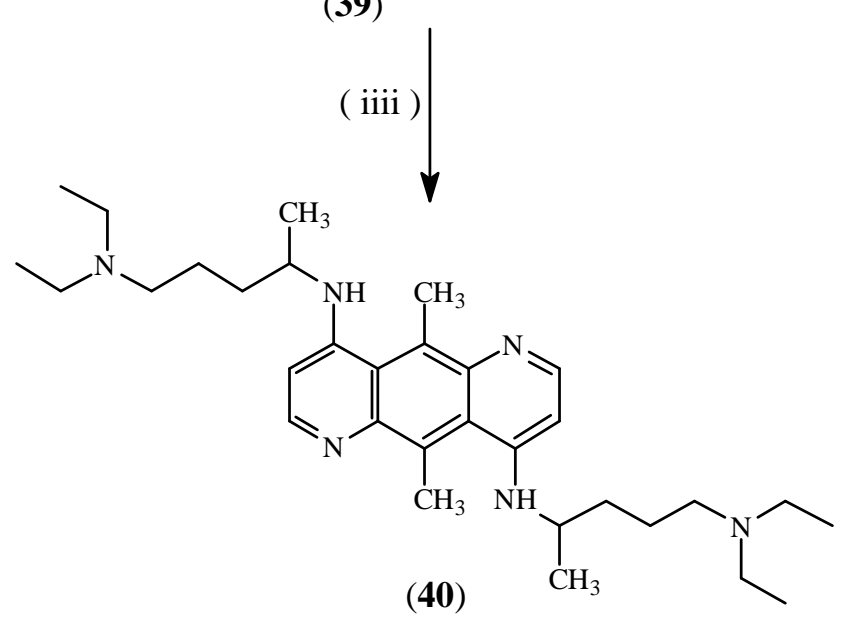<smiles>Cc1c2[nH]ccc(=O)c2c(C)c2[nH]ccc(=O)c12</smiles>

(38)

\footnotetext{
(i ) Ortoformato de trimetila, Ácido de Meldrum, $80{ }^{\circ} \mathrm{C}$, 3h; ( ii ) Éter difenílico, $250{ }^{\circ} \mathrm{C}, 5 \mathrm{~min}$ ( iii ) Oxicloreto de fósforo, refluxo $90^{\circ} \mathrm{C}, 1 \mathrm{~h}$; ( iiii ) 2-amino-5-dietilaminopentano $150^{\circ} \mathrm{C}, 14 \mathrm{~h}$
} 
Para a síntese de compostos diazatriciclos condensados, foi necessária a obtenção do precursor 2,2-dimetil-1,3-dioxano-4,6-diona (ácido de Meldrum) (34), e sua posterior condensação com ortoformato de trimetila, para a formação do intermediário 5-metoximetileno2,2-dimetil-1,3-dioxano-4,6-diona (35). O Esquema 10 apresenta a metodologia de síntese utilizada.<smiles>COC=C1C(=O)OC(C)(C)OC1=O</smiles>

( i ) $\mathrm{Ac}_{2} \mathrm{O} / \mathrm{H}_{2} \mathrm{SO}_{4}, 30 \mathrm{~min}$; ( ii ) Ortoformato de trimetila, $90{ }^{\circ} \mathrm{C}, 2 \mathrm{~h}$

Esquema 10 - Preparação do ácido de Meldrum e seu derivado

Partindo-se do ácido malônico (32) e anidrido acético, preparou-se o 2,2-dimetil-1,3dioxano-4,6-diona (34), em uma reação de condensação com acetona catalisada em meio ácido. Esta reação, bem estabelecida na literatura, ocorreu sem grandes problemas e com rendimento de 50\%. O sólido obtido foi filtrado por sucção, solubilizado em acetona e recristalizado com adição de água. O referido composto apresentou-se como um sólido cristalino branco de ponto de fusão $94-95^{\circ} \mathrm{C}$, sendo compatível com o ponto de fusão descrito em literatura $95^{\circ} \mathrm{C}$ (CASE, 1962).

O intermediário 5-metoximetileno-2,2-dimetil-1,3-dioxano-4,6-diona (35) foi obtido, então, via condensação da 2,2-dimetil-1,3-dioxano-4,6-diona (34) com ortoformato de trimetila, através de refluxo por duas horas a $90^{\circ} \mathrm{C}$. Este composto não foi isolado, fornecendo uma solução contendo a 5-metoximetileno-2,2-dimetil-1,3-dioxano-4,6-diona (35). 
Dando-se continuidade à rota de síntese proposta, utilizou-se como estratégia a reação de condensação entre a 5-metoximetileno-2,2-dimetil-1,3-dioxano-4,6-diona (35) e a 2,5dimetil-1,4-fenilenodiamina (36), para a produção do aduto do ácido de Meldrum (37), com a eliminação de metanol. O Esquema 11 representa esta reação, que se processa na proporção de $1: 2$.<smiles>COC=C1C(=O)OC(C)(C)OC1=O</smiles>

(i) $80^{\circ} \mathrm{C}, 1 \mathrm{~h}$

Esquema 11 - Preparação do aduto do ácido de Meldrum

A 2,5-dimetil-1,4-fenilenodiamina (36) foi refluxada por uma hora a $80{ }^{\circ} \mathrm{C}$ na solução obtida na etapa anterior contendo a 5-metoximetileno-2,2-dimetil-1,3-dioxano-4,6-diona (35).

Esta reação ocorreu também em bons rendimentos $(60 \%)$ e o aduto formado foi precipitado com a adição de éter de petróleo, filtrado e lavado com éter de petróleo. Este composto apresentou-se como um sólido amarelo amorfo que foi avaliado em cromatografia em camada delgada para constatação de sua pureza, e apresentou um ponto de fusão de $262{ }^{\circ} \mathrm{C}$, com decomposição, compatível com o descrito na literatura de $262{ }^{\circ} \mathrm{C}$, com decomposição (CASE, 1962).

O composto (37) foi caracterizado por espectroscopia no infravermelho (Figura 7), que mostra sinais característicos: em $3164 \mathrm{~cm}^{-1}$ deformação axial de $\mathrm{N}-\mathrm{H}$, em $3050 \mathrm{~cm}^{-1}$ deformação axial de C-H aromático e $2986 \mathrm{~cm}^{-1}$ deformação axial de C-H alifático, e as duas 
bandas em 1726 e $1670 \mathrm{~cm}^{-1}$, que são as bandas do sistema vinílogo de amida $-\mathrm{N}-\mathrm{C}=\mathrm{C}(\mathrm{C}=\mathrm{O})_{2}$ (SILVERSTEIN, 1994).

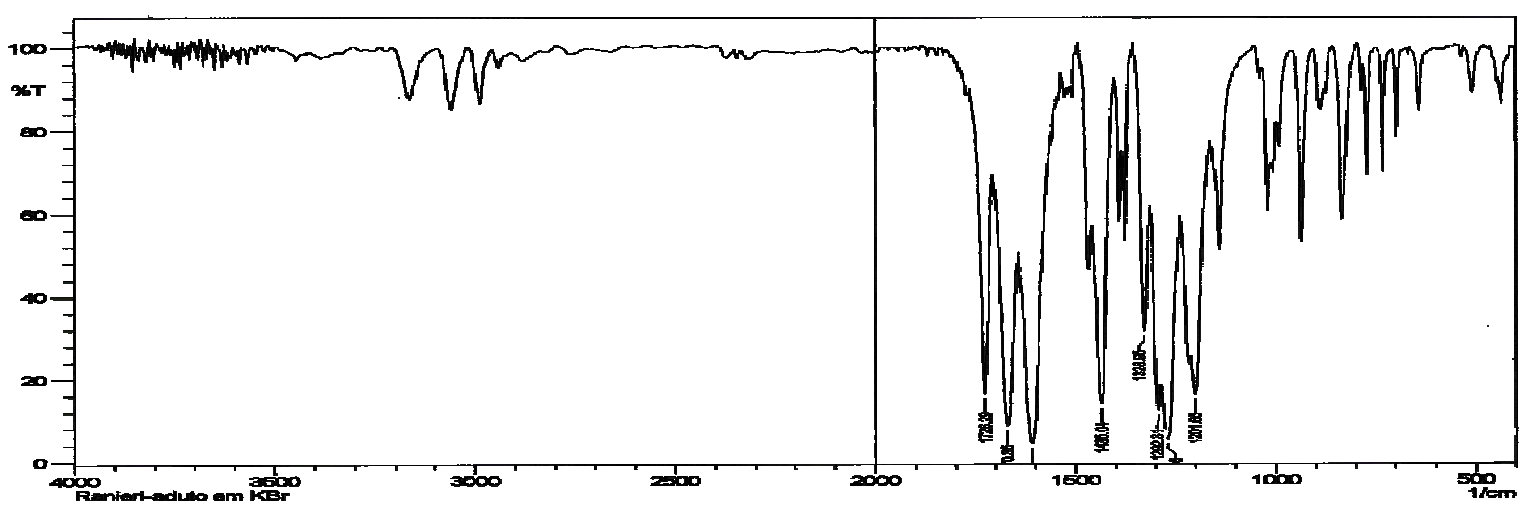

Figura 7 - Espectro de infravermelho do aduto do ácido de Meldrum (37) em KBr

Para a obtenção da pirido[2,3-g]quinolona (38) reagiu-se o aduto do ácido de Meldrum (37) em éter difenílico, que se mostrou eficiente como solvente por ter seu ponto de ebulição superior a $250^{\circ} \mathrm{C}$, ocorrendo liberação espontânea de dióxido de carbono e acetona (Esquema 12).<smiles>Cc1cc(NC=C2C(=O)OC(C)(C)OC2=O)c(C)cc1NC=C1C(=O)OC(C)(C)OC1=O</smiles>

(37)<smiles>Cc1c[nH]c2c(C)c3c(c(C)c12)c(=O)ccn3C</smiles>

(38)

( i ) Éter Difenílico à $250^{\circ} \mathrm{C}, 5 \mathrm{~min}$.

\section{Esquema 12 - Termociclização do aduto do ácido de Meldrum}

O aduto (37) foi adicionado com cuidado e aos poucos em uma solução de éter difenílico em ebulição. Esta reação tem como inconveniente a possibilidade da carbonização do 
material a ser ciclizado, mas em geral, adotando-se uma adição mais rápida do aduto ao éter difenílico, tem resultado em produtos com elevado grau de pureza e também em bons rendimentos $(58 \%)$ nas reações realizadas para este trabalho. O produto desta reação foi precipitado com n-hexano, filtrado e lavado com n-hexano. O ponto de fusão foi acima de $300{ }^{\circ} \mathrm{C}$ com decomposição, novamente em acordo com o descrito na literatura que foi acima de $300^{\circ} \mathrm{C}$ também com decomposição (CASE, 1962).

O produto (38) apresentou-se como um sólido amorfo marrom e a avaliação do grau de pureza foi feita por cromatografia em camada delgada, utilizando-se como eluente acetato de etila e os cromatogramas foram analisados sob luz ultravioleta.

O composto (38) foi também caracterizado por espectroscopia no infravermelho, apresentando as bandas características em $3250 \mathrm{~cm}^{-1}$ de deformação axial de N-H, em 1627 $\mathrm{cm}^{-1}$ a deformação angular de $\mathrm{N}-\mathrm{H}$, e em $1570 \mathrm{~cm}^{-1}$ deformação axial de $\mathrm{C}=\mathrm{O}$, em $1558 \mathrm{~cm}^{-1} \mathrm{e}$ $1519 \mathrm{~cm}^{-1}$ tem-se a banda de deformação axial de $\mathrm{C}=\mathrm{C}$ e, por fim, $1217 \mathrm{~cm}^{-1}$ mostra a banda referente à deformação axial de C-N. A Figura 8 mostra o espectro de infravermelho da pirido [2,3-g]quinolona.

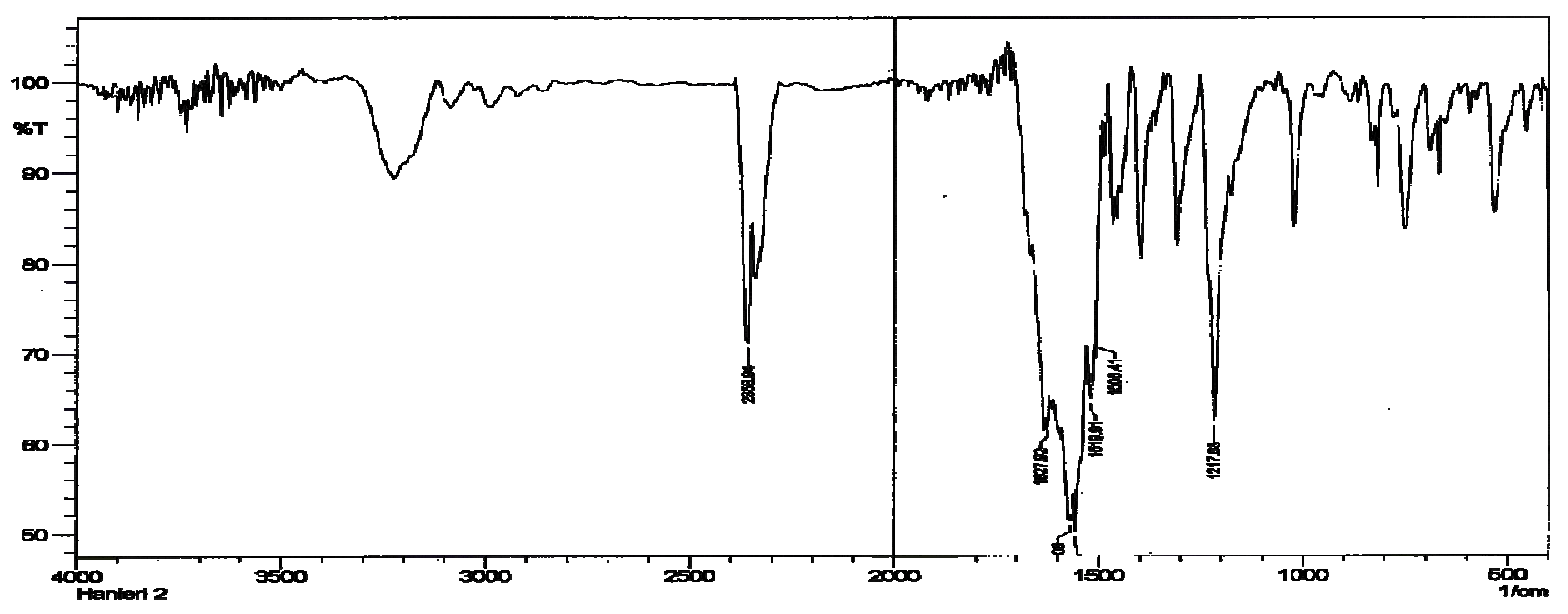

Figura 8 - Espectro de infravermelho da pirido[2,3-g]quinolona (38) em KBr 
Através de uma reação de adição seguida de uma reação de eliminação na pirido[2,3g]quinolona obtida na etapa anterior, utilizando-se como reagente o oxicloreto de fósforo, obteve-se a 4,9-dicloro-5,10-dimetil-pirido[2,3-g]quinolina (39), conforme Esquema 13.<smiles>Cc1c2[nH]ccc(=O)c2c(C)c2c(=O)cc[nH]c12</smiles>

(38)<smiles>Cc1c2nccc(Cl)c2c(C)c2c(Cl)ccnc12</smiles>

(39)

( i ) $\mathrm{POCl}_{3}, 90{ }^{\circ} \mathrm{C}, 1 \mathrm{~h}$

\section{Esquema 13 - Preparação da pirido[2, 3-g]quinolina clorada}

O produto de termociclização foi refluxado por 1 hora em oxicloreto de fósforo e, ao término da reação, este meio reacional foi neutralizado com a adição do mesmo em uma solução diluída de hidróxido de amônio (25\% v/v) e gelo. O produto clorado se apresentou como um precipitado amarelo, que depois de filtrado a vácuo e lavado com bastante água e hexano, apresentou um rendimento de $30 \%$.

$\mathrm{Na}$ tentativa de purificar o material obtido, procederam-se sucessivas recristalizações com diferentes sistemas de solventes. Além disso, a cromatografia em coluna com diferentes sistemas de solventes e gradientes de concentração foi utilizada. No entanto, melhores resultados foram obtidos pelo uso da cromatografia "flash" utilizando-se como eluente clorofórmio $100 \%$, fornecendo um rendimento de $9 \%$ do produto puro.

Este composto (39) se apresentou como um sólido amorfo amarelo, de ponto de fusão $224{ }^{\circ} \mathrm{C}$, solúvel a quente em ciclo-hexano, parcialmente solúvel em n-hexano, insolúvel em éter de petróleo e totalmente solúvel em clorofórmio. 
Para caracterizar e avaliar o grau de pureza, foi utilizada cromatografia em camada delgada empregando-se como eluente acetato de etila 100\%, seguida de cromatografia gasosa (figura 10) acoplada a espectrômetro de massas (Figura 9).

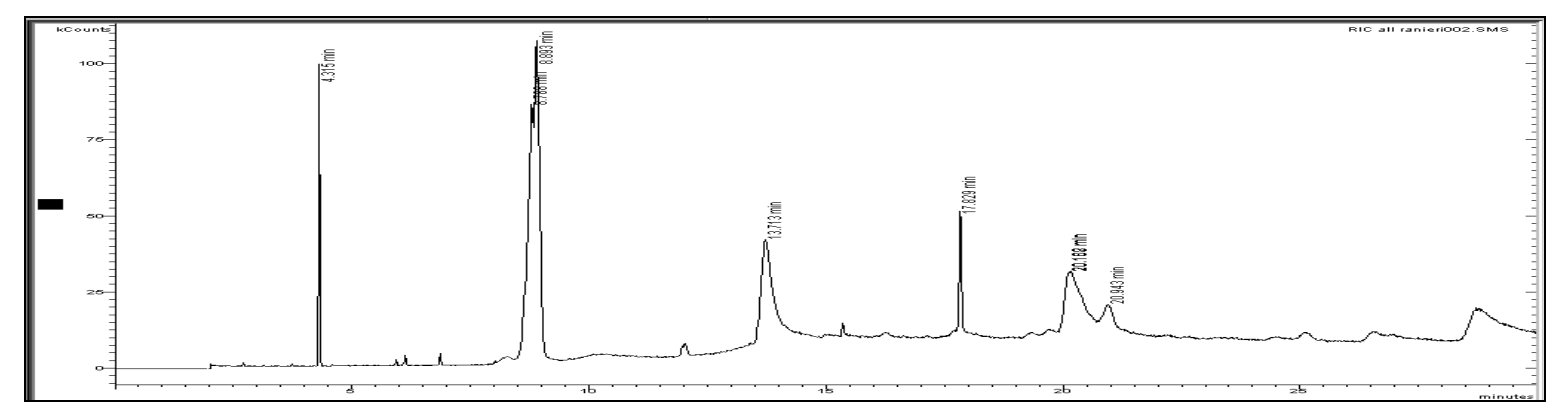

Figura 9 - Cromatograma da pirido[2,3-g]quinolina clorada (39)

Como pode ser observado na figura 9 , os picos em 8,788 e 8,893 min representam a relação m/z 276 que confere com a pirido[2,3-g]quinolina clorada (39). Pela quantificação relativa por normalização de área, o composto representa 83,64\% de pureza.

Dentro da fragmentação ocorrida no espectro de massas, podemos destacar três fragmentos que mostram com clareza a veracidade da estrutura proposta através das relações $\mathrm{m} / \mathrm{z}$, 239, 205 e 177, respectivamente (Figura 10).

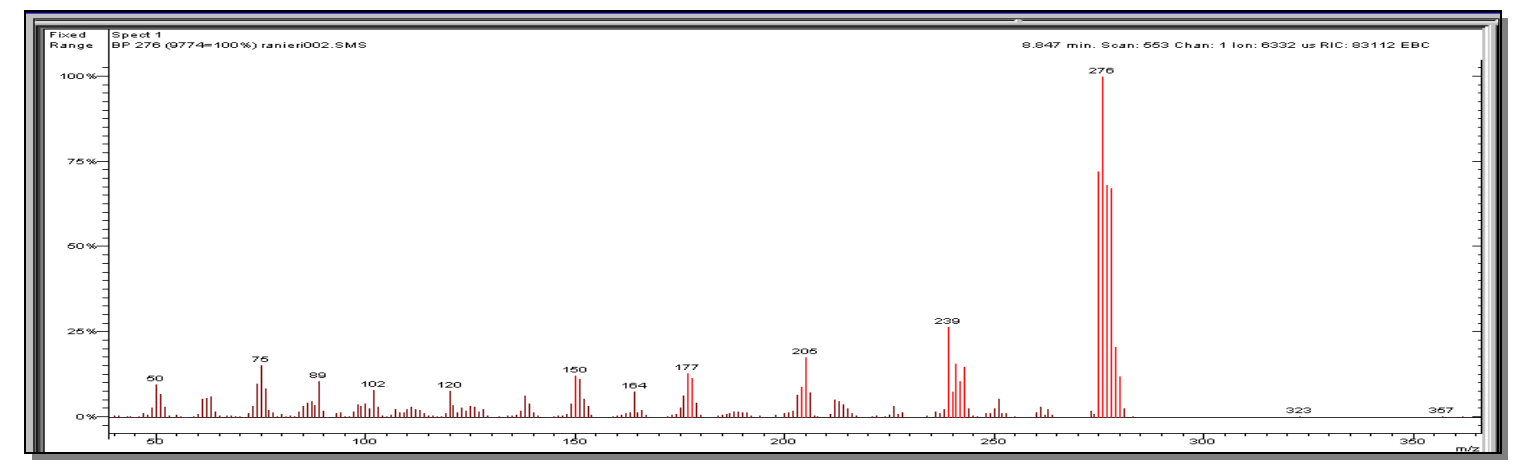


<smiles>Cc1cc2c(C)c3nccc(C)c3nccc1-2</smiles>

$(\mathrm{m} / \mathrm{z} 239)$<smiles>Cc1c2cccnc2c(C)c2cccnc12</smiles>

$(\mathrm{m} / \mathrm{z} 205)$<smiles>Cc1cnc2cc3cccnc3cc2c1</smiles>

$(\mathrm{m} / \mathrm{z} 177)$

Figura 10 - Espectro de massas da pirido[2,3-g]quinolina clorada (39) e três de seus fragmentos

Dando-se continuidade a caracterização da pirido[2,3-g]quinolina clorada (39), realizou-se uma análise no infravermelho, cujo espectro está mostrado na Figura 11.

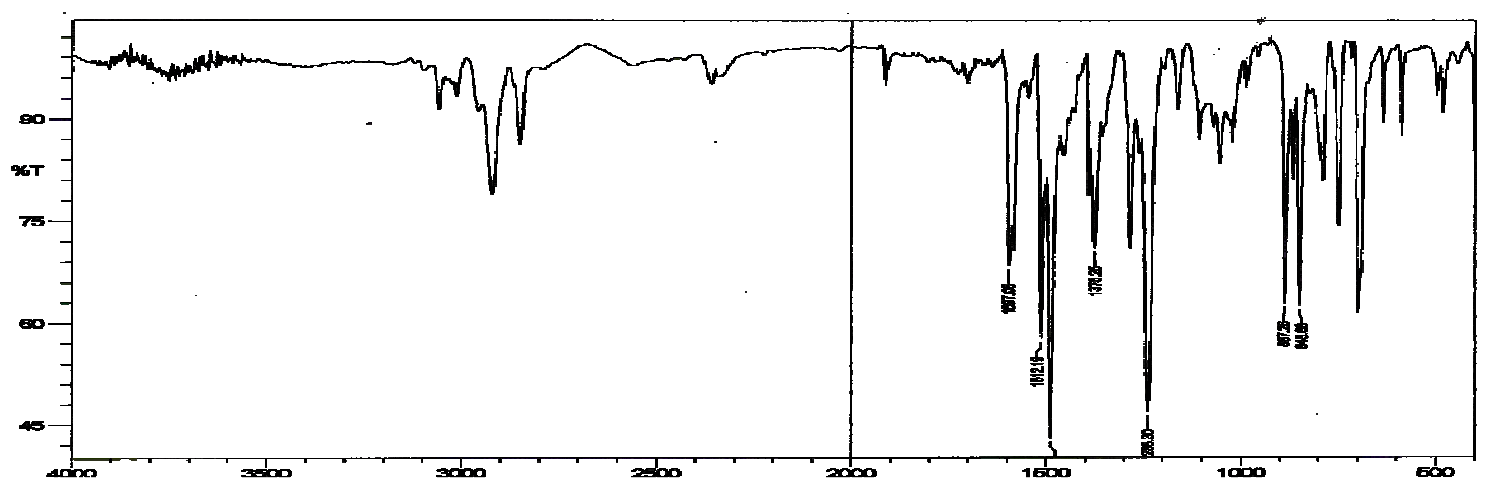

Figura 11 - Espectro de infravermelho da pirido[2,3-g]quinolina clorada (39) em KBr

Como pode ser observado, este composto apresenta absorções na região de $1597 \mathrm{~cm}^{-1}$, $1512 \mathrm{~cm}^{-1}, 1487 \mathrm{~cm}^{-1}, 1375 \mathrm{~cm}^{-1} \mathrm{e} 1238 \mathrm{~cm}^{-1}$, atribuídas às deformações axiais de $\mathrm{C}=\mathrm{C}$ e $\mathrm{C}=\mathrm{N}$ do anel aromático, que são bandas características de heterociclos nitrogenados. Em torno de $700 \mathrm{~cm}^{-1}$ pode-se notar absorções referentes à deformação angular fora do plano de C-Cl.

A análise de ressonância magnética nuclear de hidrogênio (Figura 12) mostra um singleto em 3,56 ppm (integrando 6 hidrogênios) relacionados as metilas ligadas ao anel benzênico; um dubleto em 7,53 ppm com constante de acoplamento igual a 4,2 Hz atribuído 
ao hidrogênio próximo ao cloro no anel $\pi$-deficiente; um dubleto em $8,82 \mathrm{ppm}$ com constante de acoplamento igual a 4,2 Hz referindo-se aos dois hidrogênios $\alpha$ aos nitrogênios.

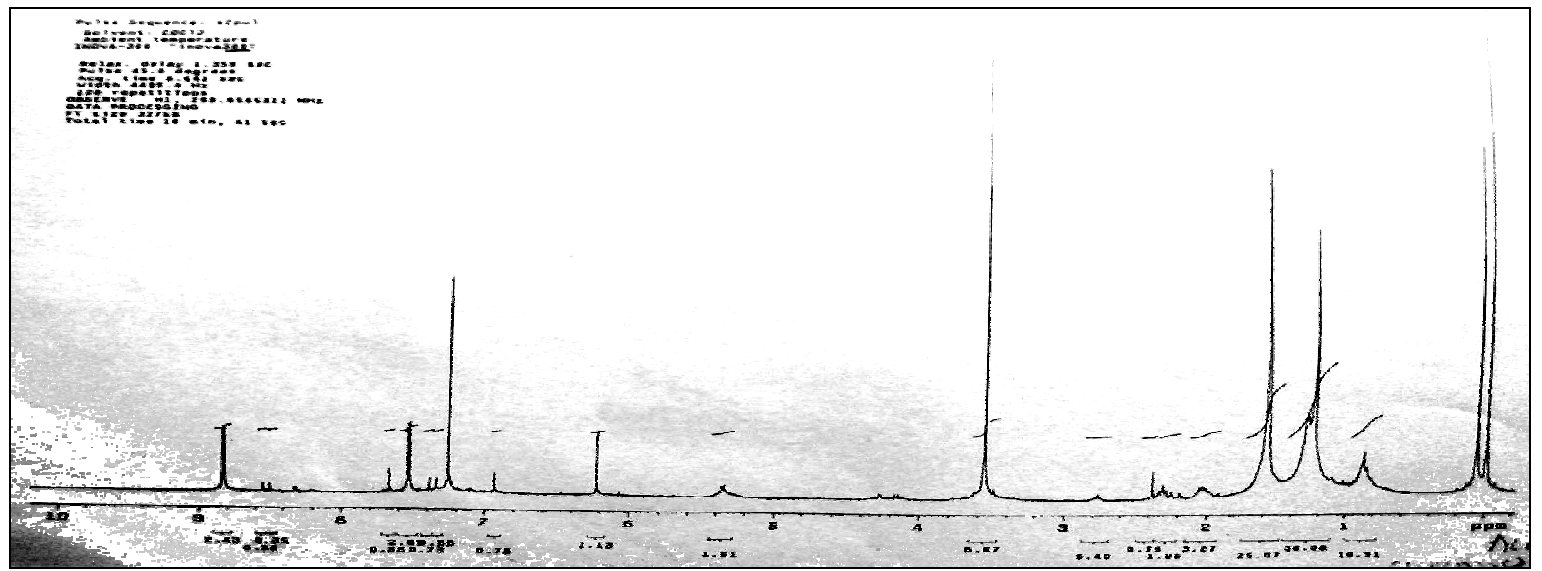

Figura 12 - Espectro de $\mathrm{RMN}^{1} \mathrm{H}$ em $200 \mathrm{MHz}$ da pirido[2,3-g]quinolina clorada (39) em $\mathrm{CDCl}_{3}$

$\mathrm{Na}$ tentativa de se obter o derivado substituído (40), foi realizada uma substituição nucleofílica aromática no núcleo pirido[2,3-g]quinolínico clorado (Esquema 14).<smiles>CCN(CC)CCCC(C)Nc1ccnc2c(C)c3c(NC(C)CCCN(CC)CC)ccnc3c(C)c12</smiles>

Esquema 14 - Preparação do derivado substituído

Neste aspecto, o composto 4,9-dicloro-5,10-dimetil-pirido[2,3-g]quinolina (39) foi refluxado com o 2-amino-5-dietilaminopentano por 8 horas a $140^{\circ} \mathrm{C}$. O meio reacional foi neutralizado através de sucessivas lavagens com uma solução aquosa a 10\% de hidróxido de amônio. 
Posteriormente, foi extraído com diclorometano (5 X $25 \mathrm{~mL}$ ), secado com sulfato de sódio anidro e, em seguida, o diclorometano foi totalmente evaporado. O produto da reação se apresentou na forma de um óleo castanho.

A purificação do material foi realizada através de cromatografia "flash", utilizando-se sílica gel para cromatografia em camada delgada, por ter uma granulometria menor e compactar mais efetivamente, e como eluente uma solução de $\mathrm{MeOH} / \mathrm{NH}_{4} \mathrm{OH}$ aumentando-se o gradiente de concentração da base de $1 \%$ até $15 \%$. O produto purificado também se apresentou como um óleo castanho, o qual foi submetido à espectroscopia na região de infravermelho (Figura 13).

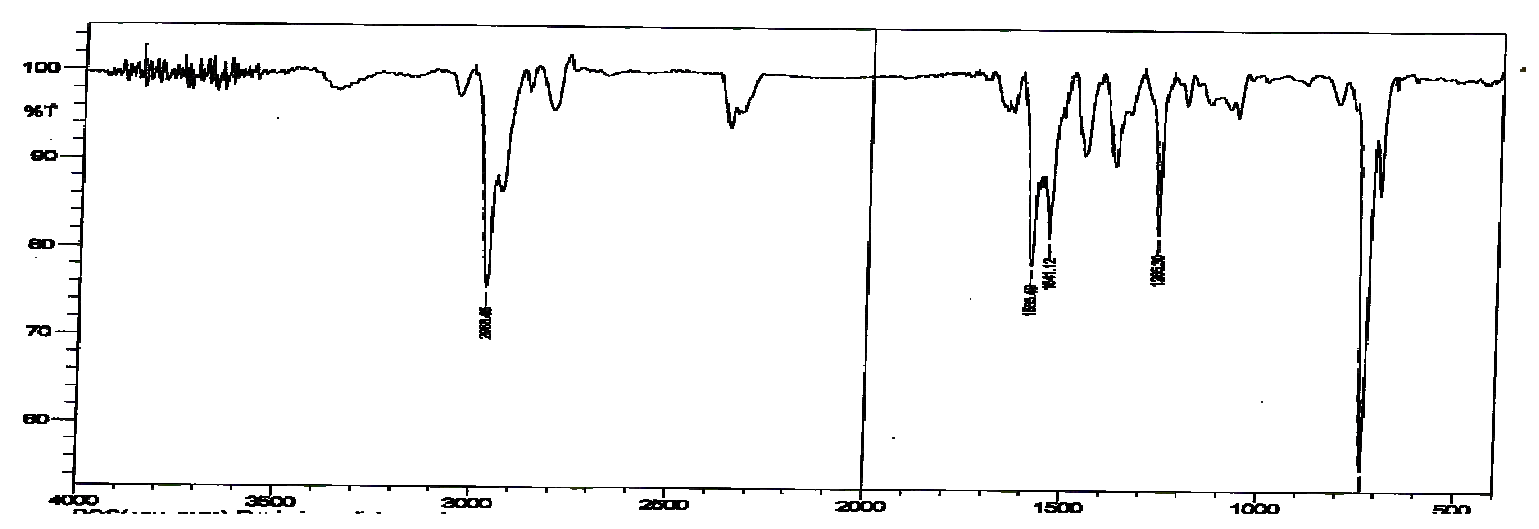

Figura 13 - Espectro de infravermelho da pirido[2,3-g]quinolina substituída (40) em $\mathrm{CH}_{2} \mathrm{Cl}_{2}$

Como pode ser observado, a falta de bandas características de amina (deformação axial de N-H na região de 3200 a $3400 \mathrm{~cm}^{-1}$ ) leva a sugerir que provavelmente a reação não ocorreu.

Neste sentido, esta reação foi repetida mudando-se as condições experimentais como tempo, temperatura e proporções dos reagentes. No entanto, após os procedimentos cromatográficos, e analisando-se sempre a fração que apresentava maior rendimento, o 
produto obtido era sempre um óleo castanho. Neste momento, análises de RMN deste produto estão em andamento na tentativa de evidenciar a sua estrutura. 


\section{AVALIAÇÃO DAS PROPRIEDADES BIOLÓGICAS}

Foi feita a avaliação das propriedades leishmanicida e tripanocida do composto 4,9dicloro-5,10-dimetil-pirido[2,3-g]quinolina (39), sendo que o mesmo não apresentou qualquer atividade. A avaliação destas propriedades foi realizada no Laboratório de Protozoologia do Departamento de Microbiologia e Parasitologia da UFSC.

A contagem dos parasitas em câmara de Newbauer em microscópio realizada com a suspensão das cavidades com controle negativo foi a mesma da contagem obtida a partir das cavidades com o composto 4,9-dicloro-5,10-dimetil-pirido[2,3-g]quinolina (39). 


\section{PARTE EXPERIMENTAL}

\subsection{Equipamentos}

As análises por espectroscopia de ressonância magnética nuclear de ${ }^{1} \mathrm{H}$ e ${ }^{13} \mathrm{C}$, foram executadas em equipamento Inova $300 \mathrm{MHz}$, na Universidade Federal do Rio Grande do Sul. Tetrametilsilano (TMS) foi empregado como padrão interno e $\mathrm{CDCl}_{3}$ como solvente.

Os espectros de massa foram realizados em espectrômetro Shimadzu - CGMS-QP2000-A, no IPTB/FURB.

Os espectros de infravermelho foram obtidos em um espectrofotômetro Shimadzu Prestige - 21A pertencente ao Departamento de Química da FURB, e empregando-se pastilhas de $\mathrm{KBr}$.

As análises cromatográficas foram realizadas em um cromatógrafo gasoso $17 \mathrm{~A}$ da Shimadzu no IPTB/FURB.

Todas as medidas de ponto de fusão não corrigidas foram realizadas em aparelhos de aquecimento gradual do tipo Kofler (Microquímica APF-301).

\subsection{Reagentes e solventes}

Todos os solventes e reagentes utilizados foram de pureza analítica e de procedência Merck, Aldrich Chemical Company, Vetec e Carlo Erba.

Foram utilizados reagentes e solventes comerciais sem prévia purificação, exceto o oxicloreto de fósforo e o 2-amino-5-dietilaminopentano que foram destilados previamente.

Para a purificação dos compostos sintetizados empregaram-se técnicas de recristalização, extração com solventes e cromatografia em coluna, esta última utilizando 
sílica gel como adsorvente. Todas as reações foram acompanhadas por cromatografia em camada delgada (CCD) utilizando-se sílica gel $60 \mathrm{GF}_{254}$, (adquirida da Merck) e analisadas sob luz ultravioleta.

\subsection{Procedimentos de Síntese}

\subsubsection{Preparação da 2,2-dimetil-1,3-dioxano-4,6-diona (Ác. de Meldrum) (34)}<smiles>CC1(C)OC(=O)CC(=O)O1</smiles>

Em Erlenmeyer de $250 \mathrm{~mL}$ foram adicionados à temperatura ambiente, ácido malônico (26 g, 0,25 mol), anidrido acético (30,6 g, 30 mL, 0,30 mol) e ácido sulfúrico (0,75 mL).

O meio reacional, sob agitação magnética, foi resfriado em banho de gelo e adicionou-se, gota a gota, $20 \mathrm{~mL}$ de acetona $(14,04 \mathrm{~g}, 0,27 \mathrm{~mol})$ mantendo-se a temperatura do meio reacional sempre abaixo de $25^{\circ} \mathrm{C}$.

A solução foi agitada por mais 30 minutos em banho de gelo e levada ao refrigerador por 24 horas.

O sólido cristalino foi coletado por filtração a vácuo e lavado com água gelada, sendo recristalizado pela dissolução em acetona $(55 \mathrm{~mL})$ à temperatura ambiente e posterior adição de água destilada (110 mL), sendo então, colocado em banho de gelo por 1 hora.

O sólido obtido foi filtrado a vácuo, lavado com água gelada e seco em estufa a vácuo $\left(25 \mathrm{mmHg}\right.$ e $\left.25^{\circ} \mathrm{C}\right)$. 
$\mathrm{O}$ ponto de fusão do composto foi de $94-95^{\circ} \mathrm{C}$, que esta em acordo com aquele descrito na literatura que é $95^{\circ} \mathrm{C}(\mathrm{CASE}, 1962)$ e o rendimento obtido nesta reação foi de $50 \%$.

\subsubsection{Preparação do 2,5-dimetil-1,4-bis-[(2,2-dimetil-4,6-dioxo-1,3-dioxano-5-ilideno- metil)amino]-benzeno (Aduto do ác. de Meldrum) (37)}<smiles>Cc1cc(NC=C2C(=O)OC(C)(C)OC2=O)c(C)cc1NC=C1C(=O)OC(C)(C)OC1=O</smiles>

Em um balão de fundo redondo de $125 \mathrm{~mL}$, o ácido de Meldrum (10,08 g, 70 mmols) foi refluxado com excesso de ortoformato de trimetila $(100 \mathrm{~mL})$ por 2 horas a $80^{\circ} \mathrm{C}$.

A esta solução, a 2,5-dimetil-1,4-fenilenodiamina (4,08 g, $30 \mathrm{mmols})$ foi adicionada e esta mistura foi refluxada por mais uma hora.

O produto desta reação foi precipitado com éter de petróleo, filtrado a vácuo e lavado com éter de petróleo.

Sólido amarelo (60\%): P.F. $262^{\circ} \mathrm{C}$ (dec.) (lit $262^{\circ}$ dec.)(CASE,1962); IV (KBr, cm $\left.{ }^{-1}\right)$ : 3164, 3050, 2986, 1726, 1670. 


\subsubsection{Preparação da pirido[2,3-g]quinolona (38)}<smiles>Cc1c2[nH]ccc(=O)c2c(C)c2[nH]ccc(=O)c12</smiles>

Em um balão de fundo redondo de $50 \mathrm{~mL}$ o bis-aduto do ácido de Meldrum (37) (0,416 g, $1 \mathrm{mmol})$ correspondente foi refluxado em éter difenílico (20 mL) em ebulição ( 250 $\left.{ }^{\circ} \mathrm{C}\right)$ por, no máximo, 5 minutos.

A mistura foi resfriada à temperatura ambiente, e a ela foram adicionados $20 \mathrm{~mL}$ de $\mathrm{n}$ hexano. O sólido que precipitou da mistura foi filtrado a vácuo e lavado com n-hexano.

Sólido marrom (58\%): P.F. > 300 ${ }^{\circ} \mathrm{C}$ (dec.) (lit. acima de $300^{\circ} \mathrm{C}$ ) (CASE, 1962); IV $\left(\mathrm{KBr}, \mathrm{cm}^{-1}\right): 3250,1627,1570,1558,1519,1217$.

\subsubsection{Preparação da 4,9-dicloro-5,10-dimetil-pirido[2,3-g]quinolina (39)}<smiles>Cc1c2nccc(Cl)c2c(C)c2nccc(Cl)c12</smiles>

A pirido[2,3-g]quinolona (38) (0,5 g, 0,026 mol) adicionou-se o oxicloreto de fósforo recém destilado $(12,5 \mathrm{~mL})$ em um balão de fundo redondo de $100 \mathrm{~mL}$. A mistura foi refluxada por 1 hora a $90^{\circ} \mathrm{C}$.

O meio reacional foi adicionado a uma solução de hidróxido de amônio $25 \%$ em banho de gelo e com agitação, gota a gota, mantendo sempre o meio gelado e básico. 
Ao término da adição, o precipitado amarelo que se formou foi filtrado, lavado com bastante água e logo após com n-hexano.

Sólido amarelo (9\%): P.F :224º C; IV (KBr, cm $\left.{ }^{-1}\right)$ : 1597, 1512, 1487, 1375, 1238, 700. $\mathrm{RMN}^{1} \mathrm{H}\left(\mathrm{CDCl}_{3}, 200 \mathrm{MHz}\right) \delta 3,56(\mathrm{~s}, 6 \mathrm{H}) ; 7,53(\mathrm{~d}, \mathrm{~J}=4,1 \mathrm{~Hz}, 2 \mathrm{H}) ; 8,82(\mathrm{~d}, \mathrm{~J}=4,1 \mathrm{~Hz}, 2 \mathrm{H})$; $\mathrm{RMN}{ }^{13} \mathrm{C}\left(\mathrm{CDCl}_{3}, 50 \mathrm{MHz}\right) \delta 16,2 ; 126,2 ; 129,3 ; 138,2 ; 148,6 ; 160,7 ; \mathrm{MS}(\mathrm{EI}) 276\left(\mathrm{M}^{+}\right)$.

\subsubsection{Preparação da pirido[2,3-g]quinolina substituída (40)}<smiles>CCN(CC)CCCC(C)Nc1ccnc2c(C)c3c(NC(C)CCCN(CC)CC)ccnc3c(C)c12</smiles>

A 4,9-dicloro-5,10-dimetil-pirido[2,3-g]quinolina (39) $(0,27 \mathrm{~g}, 0,96 \mathrm{mmol})$ foi refluxada com 2-amino-5-dietilaminopentano $(0,3 \mathrm{~g}, 2,3 \mathrm{mmols})$ por 8 horas a $140^{\circ} \mathrm{C}$. Após resfriar a solução, procederam-se várias lavagens com hidróxido de amônio 10\%, seguida de uma extração com diclorometano (5 x 25mL). A fase orgânica foi seca com sulfato de sódio anidro e o solvente retirado em evaporador rotatório, fornecendo um óleo castanho, que foi purificado por "flash" cromatografia utilizando-se metanol/hidróxido de amônio, verificado anteriormente como melhor sistema solvente em cromatografia em camada delgada, em gradiente de concentração da base de $1 \%$ a 15\%, obtendo-se um óleo castanho. 


\section{PROTOCOLOS PARA AVALIAÇÃo DA ATIVIDADE BIOLÓGICA}

A realização das análises das propriedades biológicas foi conduzida conforme descrito em Pizzolatti et al. (2002) e Muelas-Serano et al. (2000).

\subsection{Composto avaliado (4,9-dicloro-5,10-dimetil-pirido[2,3-g]quinolina) (39)}

Este foi previamente solubilizado em dimetilsulfóxido (DMSO) na concentração de 50 $\mathrm{mg} / \mathrm{mL}$, filtrado em membrana de $0,22 \mu \mathrm{m}$ e mantido a $4^{\circ} \mathrm{C}$ até o uso. Como drogas controle foram utilizadas o cristal violeta e benzonidazol (Rochagan $\left.{ }^{\circledR}\right)$ para os experimentos com $T$. cruzi e a anfotericina B para Leishmania spp.

\subsection{Parasitas}

Neste estudo foram utilizadas formas epimastigotas de cultura, tripomastigotas sangüíneas e amastigotas de cultivo celular da cepa Y de $T$. cruzi e amastigotas de cultivo celular e promastigotas de cultura de Leishmania braziliensis (cepa L-2904), L. amazonensis (cepa H1) e L. chagasi (cepa PH8) mantidos no Laboratório de Protozoologia da UFSC.

\subsection{Avaliação "in vitro" da atividade antiparasitária da 4,9-dicloro-5,10-dimetil-pi- rido[2,3-g]quinolina (39) contra formas epimastigotas de $T$. cruzi e promastigotas de Leishmania spp}

Os ensaios foram realizados em placas de culturas de 96 orifícios Nunc ${ }^{\circledR}$, contendo

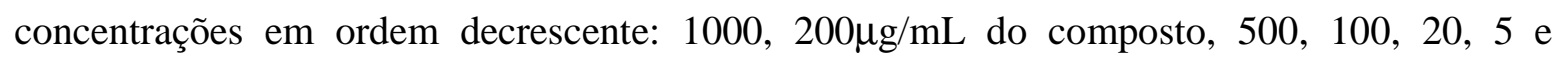


$1 \mu \mathrm{g} / \mathrm{mL}$ do composto em um volume final de $200 \mu \mathrm{L}$ contendo $5 \times 10^{6}$ epimastigotas ou promastigotas/mL.

6.4 Avaliação "in vitro" da atividade tripanocida e leishmanicida da 4,9-dicloro-5,10dimetil-pirido[2,3-g]quinolina (39) contra formas amastigotas de T. cruzi e Leishmania spp

A avaliação da atividade tripanocida e leishmanicida contra amastigotas foi ensaiada em linhagem celular Vero. 


\section{CONCLUSÃO}

A síntese da 4,9-dicloro-5,10-dimetil-pirido[2,3-g]quinolina aconteceu através de 3 etapas reacionais, com baixo rendimento, a partir da 2,5-dimetil-1,4-fenilenodiamina comercial.

A metodologia proposta para a síntese do núcleo pirido[2,3-g]quinolínico substituído com o nucleófilo nitrogenado 2-amino-5-dietilaminopentano apresentou dificuldades. Foram feitas várias tentativas de reação variando parâmetros como tempo e temperatura, mas sem sucesso.

Portanto, é necessária a busca de melhores condições de reação de substituição e a reação deve ser repetida visando melhores resultados, e complementar a caracterização deste produto através de técnicas espectroscópicas convencionais para posterior avaliação de suas propriedades leishmanicida e tripanocida "in vitro". 


\section{REFERÊNCIAS BIBLIOGRÁFICAS}

AUCLAIR, C.; Arch. Biochem. Biophys., v. 259, n. 1, 1987.

BANG-CHI, C.; Meldrum's acid in organic synthesis, Heterocycles, v. 32, p. 529-597, 1991.

BASAnO, S. A.; CAMARGO, L. M. A. Revista Brasileira de Epidemiologia, v. 7, n. 3, p. 328-337, 2004.

CASE, F.; KOFT, E.; J.Org.Chem., v. 5, p. 865, 1962.

CASSIS, R.; TAPIA, R.; VALDERRAMA, J. A. Synthesis of 4(1H)-quinolones by thermolysis of arylaminomethylene Meldrum's acid derivates. Synth. Commun., v. 15, n. 2, p.125-133, 1985.

CHEIKH, A. B. Synthesis of $\alpha$-cyano carbonyl compounds by flash vacum thermolysis of (alkylamino) methylene derivatives of Meldrum's acid. Evidence for facile 1,3-shifts of alkylamino and alkilthio group in indoylketene intermediates. J. Chem. Soc, v. 56, p. 970$975,1991$.

CHEVAlier, I. et. al. Chem. Pharm. Bull. v. 48, n. 12, p. 1886-1889, 2000.

CIRINO, J. V.; BELletATO, P.; DANTAS, S. O. Química Nova, v. 28, n. 1, p. 30-36, 2005.

DANTAS, S. O.; GALVÃO, D. S., An investigation of the electronic-structure of the antitumor drug ellipticine and its derivatives. 2. spectroscopic indo ci study, TheochemJournal of Molecular Structure. v. 89, n. 3-4, 437-449, 1992.

GALLO, S. et. al., Europian Journal of Medicinal Chemistry, v. 38, p. 19-26, 2003. 
GOnTIJO, B.; CARVAlHO. M. L. R., Revista da Sociedade Brasileira de Medicina tropical, v. 36, n. 1, p. 71-80, 2003.

GRAF, G. I. et. al. Tetrahedron. v. 58, p. 9095-9100, 2002.

HALL, C. M; et al. Rapid Commun. Mass Spectrom. v. 15, p. 862-866, 2001.

IGLÉSIAS, J. D. F. Aspectos Médicos das Parasitoses Humanas. Rio de Janeiro: Editora Médica e Científica, p. 53-64, 1997.

KATRITZKY, A. R.; REES. C. W. Naphthyridines, pyridoquinolines, anthyridines and similar compounds. Comprehensive Heterocyclic Chemistry, $1^{\text {a }}$ ed. Oxford. Ed. Pergamon Press, v.2, p. 581-689, 1984.

MACNAB, H. Chem. Soc. Ver., v. 7, p. 345-358, 1978.

MATIAS, C.; MAHAMOUND, A.; Heterocycles, v. 1624, p. 43, 1996.

McCAUSTLAND, D. J.; CHENG, C. C., Journal of Heterocyclic Chem. v. 7, n. 3, p. 467472, 1970.

McMURRY, J. Química Orgânica. 4ª ed., Rio de Janeiro: LTC, 1997.

MOLOCK, F. F. Journal of Heterocycles Chem. v. 20, p. 681, 1983.

MORAES, R. G.; LEITE, I. C.; GOULART, E. G. Parasitologia e Micologia Humana. $3^{\mathrm{a}}$ ed. Rio de Janeiro: Cultura Médica, p. 91-94, 1988.

NEVES, D. P. Parasitologia Humana. 9ª ed., São Paulo: Ateneu, p. 34-114, 1997. 
PESSOA, S. B.; MARTINS, A. V. Parasitologia Médica. $11^{\text {a }}$ ed. Rio de Janeiro: Guanabara Koogan, p. 91-96 e 216-219, 1988.

PICÓ, Y. et. al. Synthesis. v. 4, p. 549-556, 2001.

QUAST, H.; SHON, N., Liebigs Ann.Chem., p.133-146, 1984.

REY, L. Parasitologia. $2^{\text {a }}$ ed. Rio de Janeiro: Guanabara Koogan, p. 192, 1991.

SILVERSTEIN, R. M.; BASSLER, G. C.; MORRIL, T. C., Identificação espectrométrica de compostos orgânicos. Guanabara Koogan, $5^{\text {a }}$ ed., Rio de Janeiro, 1994.

RATH, S. et. al. Antimoniais empregados no tratamento da leishmaniose: estado da arte. Química Nova, v. 26, n. 4, 2003.

SHARPLES, D. et. al. European Journal of Medicinal Chem. v. 40, p. 195-202, 2005.

SOLOMONS, T. W. G. Química Orgânica. 7ª ed. Rio de Janeiro: LCT, 2001. 